\title{
MACADEMY Of Management

\section{Organizational Affective Tone: A Meso Perspective on the Origins and Effects of Consistent Affect in Organizations}

\begin{tabular}{|c|l|}
\hline Journal: & Academy of Management Journal \\
\hline Manuscript ID & AMJ-2016-0671.R2 \\
\hline Manuscript Type: & Revision \\
\hline Keywords: & $\begin{array}{l}\text { Survey < Quantitative Orientation < Research Methods, Mood and } \\
\text { emotions < Attitudes, Cognitions, and Affect < Organizational Behavior }< \\
\text { Topic Areas, Stress, strain, and well-being < Attitudes, Cognitions, and } \\
\text { Affect < Organizational Behavior < Topic Areas }\end{array}$ \\
\hline Abstract: & $\begin{array}{l}\text { Grounded in an open systems perspective, we build and test new theory } \\
\text { about how the kinds of industries in which an organization participates } \\
\text { influences organizational affective tone and connects to workforce strain. } \\
\text { We propose that the more an organization's activities lie in consumer- } \\
\text { centric industries (e.g., service, retail), the more positive and less negative } \\
\text { the organization's affective tone. We connect consumer-centric industry } \\
\text { participation and affective tone by explaining how personnel policies and } \\
\text { organizational structure generate and sustain consistent positive and } \\
\text { negative affect throughout an organization. Additionally, we examine the } \\
\text { effects of organizational affective tone on workforce strain. The results of a } \\
\text { survey-based study of 24,015 human resource managers, top } \\
\text { management team members, and employees of } 161 \text { firms largely support } \\
\text { our predictions. We discuss the implications of considering macro } \\
\text { contextual factors for understanding affect in organizations. }\end{array}$ \\
\hline
\end{tabular}




\title{
Organizational Affective Tone: A Meso Perspective on the Origins and Effects of Consistent Affect in Organizations
}

\author{
Andrew P. Knight \\ Washington University in St. Louis \\ One Brookings Drive \\ St. Louis, MO 63130 \\ USA \\ knightap@wustl.edu \\ Jochen I. Menges \\ WHU - Otto Beisheim School of Management \\ Erkrather Str. 224a \\ 40233 Düsseldorf \\ Germany \\ jochen.menges@whu.edu \\ Heike Bruch \\ University of St. Gallen \\ Dufourstrasse 40a \\ 9000 St. Gallen \\ Switzerland \\ heike.bruch@unisg.ch
}

\section{Acknowledgements}

The first two authors contributed equally to this manuscript; authorship is alphabetical. We are extremely grateful to Associate Editor Brent Scott and three anonymous reviewers for constructive and insightful feedback. We also thank Sigal Barsade, Nancy Rothbard, Amanda O'Neill, Lakshmi Ramarajan, and members of the GOMERs working paper group at Washington University in St. Louis for helpful suggestions on prior versions of this manuscript. 


\title{
Organizational Affective Tone: A Meso Perspective on the Origins and Effects of Consistent Affect in Organizations
}

\begin{abstract}
Grounded in an open systems perspective, we build and test new theory about how the kinds of industries in which an organization participates influences organizational affective tone and connects to workforce strain. We propose that the more an organization's activities lie in consumer-centric industries (e.g., service, retail), the more positive and less negative the organization's affective tone. We connect consumer-centric industry participation and affective tone by explaining how personnel policies and organizational structure generate and sustain consistent positive and negative affect throughout an organization. Additionally, we examine the effects of organizational affective tone on workforce strain. The results of a survey-based study of 24,015 human resource managers, top management team members, and employees of 161 firms largely support our predictions. We discuss the implications of considering macro contextual factors for understanding affect in organizations.
\end{abstract}

Keywords: Affective tone, Workforce strain, Open systems theory, Meso perspective, Industry

An emerging stream of theory and research suggests that organizations possess overarching affective characteristics_consistent feeling states, common assumptions and values regarding emotion, and homogeneous expectations about affect (Barsade \& O’Neill, 2014; Menges \& Kilduff, 2015; O’Neill \& Rothbard, In Press; Parke \& Seo, In Press). One overarching characteristic that has important implications for organizations and employees is organizational affective tone — consistent positive and negative feelings held in common across organizational members (George, 1990). Scholars (e.g., Demerouti, Bakker, Nachreiner, \& Schaufeli, 2001; Ganster \& Rosen, 2013) have long implicated characteristics of the organizational context in which people work as inputs to workforce strain— a "set of adverse psychological, physiological, and behavioral reactions to work stressors" (Côté, 2005: 509). However, it is only in recent years that research has begun to suggest that an organizational context characterized by consistent positive affect across employees may be a contextual resource that ameliorates strain, 
while consistent negative affect may serve as a contextual demand that heightens strain (e.g., Barsade \& O’Neill, 2014; O’Neill \& Rothbard, In Press). Given the real and substantial costs of workforce strain for organizations_-such as healthcare expenses and productivity lost to absenteeism (e.g., Côté, 2005; Davis, Collins, Doty, Ho, \& Holmgren, 2005)—understanding the factors that contribute to organizational affective tone is important both theoretically and practically. The purpose of this paper is to advance understanding of affect in organizations by building and testing a conceptual model that explains the origins of organizational affective tone and its effects on workforce strain.

Why do some organizations have a relatively positive affective tone, while others have a relatively negative tone? Knowledge about the factors and processes that contribute to collective affect has, to date, largely surfaced from theory and research on small groups and teams (Menges \& Kilduff, 2015). According to this literature (e.g., Barsade \& Knight, 2015), the members of small groups and teams are prone to share similar feeling states due to micro and interactional processes, such as emotional contagion (Barsade, 2002) and collective sensemaking (Bartel \& Saavedra, 2000). The theory and findings in this literature, although informative about affective dynamics in small groups, are likely of limited relevance for explaining the affective characteristics of larger collectives, such as entire organizations. Whereas the members of a small group frequently interact directly with one another, providing an opportunity for group members to consciously or unconsciously share their affect with one another, it is rare for all members of an entire organization to come together. And, whereas a single person's affect can significantly influence the feelings of others in a small group (Barsade, 2002; Sy, Côté, \& Saavedra, 2005), the impact of any one person's feeling state is diluted as a collective grows in 
size. Understanding the overarching affective characteristics of organizations, such as organizational affective tone, thus likely requires new theoretical perspectives.

We propose a new theoretical model about the origins of organizational affective tone and its effects on workforce strain by building upon a robust conceptual foundation from organization theory—an open systems perspective (Katz \& Kahn, 1978; Thompson, 1967). A central tenet of an open systems perspective is that how an organization creates value- that is, the kinds of industries in which it competes and where in the value chain it operates-provides clues needed to understand why it possesses certain characteristics. We posit that organizations vary in affective tone, in part, because they compete in different kinds of industries, which hold different assumptions regarding the relevance and value of positive and negative affect. In particular, we suggest that the more an organization operates in consumer-centric industries-in which value is created through direct interactions with end users or consumers, such as service and retail - the more likely it is that the organization uses processes and structures that encourage consistent positive affect and inhibit consistent negative affect. Further, we suggest that organizational affective tone acts as a contextual factor that influences workforce strain. We test our conceptual model, depicted in Figure 1, using survey data from 24,015 executives, human resource managers, and employees of 161 companies.

Insert Figure 1 about here

This research makes three main contributions to the literature. First, we offer a novel answer to the question of why some organizations are characterized by consistent positive affect, while others are characterized by consistent negative affect. In contrast to existing theory and research on affect in organizations, which highlight local and micro processes that precipitate 
moods and emotions, our model and findings offer a more distal and macro explanation: An organization's overarching affective tone is, at least in part, rooted in the kinds of industries in which the organization operates and, specifically, in the extent to which the consumer or end user is central to the organization's activities. Our overarching theoretical model and empirical findings point to macro factors thus far overlooked to explain why consistent affect emerges across the members of large collectives.

Second, we delineate a set of mechanisms_-personnel practices and elements of organizational structure - that connect this distal and macro factor to organizational affective tone. By identifying organizational characteristics that embed affective tone, we explain specifically how consistent affect can emerge across the members of a large collective who may work in separate units and never share common experiences together. In so doing, we build a bridge between a topic traditionally studied by scholars focused on a more macro level—industry context—and one traditionally studied by scholars focused on a more micro level—affect. We thus offer a meso perspective, which integrates theoretical perspectives and concepts from macro organizational behavior with those from micro organizational behavior to yield new insights into the topic of affect in organizations and open interesting directions for future theory and research (House, Rousseau, \& Thomas-Hunt, 1995; Rousseau \& House, 1994).

Third, we theorize about and examine the effects of organizational affective tone on workforce strain. Existing theory and research suggest that those who work within the same group context often exhibit similar levels of strain because they encounter similar demands and resources in the course of their work (Demerouti et al., 2001). We extend this work, which to date has focused on contextual factors like the physical environment or workload, by explaining how organizational affective tone serves as a contextual factor that either heightens or decreases 
workforce strain. Further, our large-scale survey study complements and extends prior research on the effects of collective affect on workforce strain, which consists mainly of detailed empirical examinations of relatively small organizations and departments within individual industries like long-term health care (Barsade \& O’Neill, 2014) and firefighting (O’Neill \& Rothbard, In Press). The findings of our analysis of a large sample of 161 different firms suggest that organizational affective tone not only has an effect on workforce strain in a wide range of industries, but also that this effect itself may be shaped by the industries in which organizations operate.

\section{THEORETICAL FRAMEWORK}

To date, researchers have most commonly studied converging affect in small groups and teams_ — or group affective tone (George, 1996) — as akin to the psychological experience of mood, which is a diffuse and mild feeling state that can fluctuate over time (Barsade \& Knight, 2015). In studying affective tone, researchers have typically distinguished between two broad dimensions of feeling states in small groups_-positive states (e.g., feelings of enthusiasm, excitement, or joy) and negative states (e.g., feelings of anxiety, tension, or frustration) (Knight \& Eisenkraft, 2015). To constitute collective affect—and something that is a characteristic of the group - the positive or negative feeling state must be consistent among group members (George, 1990). Research suggests that the members of small groups are prone to share affect due to a set of micro and interactional processes that tend to characterize collocated situations. Small group settings are conducive to the micro process of emotional contagion, in which group members mimic one another and, through facial feedback, develop similar feelings (Barsade, 2002; Hatfield, Cacioppo, \& Rapson, 1994). Further, the members of a small group pursuing a shared goal regularly are exposed to common events that have similar implications for group members 
and, thus, prompt similar affective experiences (Sy et al., 2005; Van Kleef et al., 2009). It is through these kinds of micro processes, theory and research suggest, that affective tone emerges in small groups and teams (George, 1996; Kelly \& Barsade, 2001).

Our interest in this paper lies in understanding converging affect among the members of collectives larger than a small group, such as among the members of an entire organization. In collectives larger than a small group, people work in different teams, on different projects, and often in different locations. All members of an organization—even a relatively small one—may never interact directly and simultaneously with one another. Although there are rare instances when the members of a large organization simultaneously attend to a common stimulus_Apple employees attending the virtual memorial service for company founder Steve Jobs, for example—such events are atypical given the disruption to organizational functioning (e.g., Apple closed all of its stores during this time). Without direct interactions among all employees or frequent exposure to common events, it is unlikely that the interpersonal mechanisms found to underlie collective affect in small groups and teams can account for the emergence of consistent affect in larger organizations (Song, Foo, \& Uy, 2008; Totterdell, Wall, Holman, Diamond, \& Epitropaki, 2004).

And yet, although the processes are relatively less well understood, theorists suggest that affect can converge even in large organizations (e.g., Barsade \& O’Neill, 2014; Menges \& Kilduff, 2015; Parke \& Seo, In Press). Rather, however, than being akin to a shared mood, as in a small and collocated group, affective tone in a large and dispersed organization can be conceptualized as a form of descriptive norm - the "typical or normal" (Cialdini, Reno, \& Kallgren, 1990: 1015) way that people in an organization feel. Even though the nature of the construct differs from the small group level (i.e., shared mood) to the organizational level (i.e., 
descriptive norm), its concern with consistent, similar, and converging affect in collectives remains the same (e.g., Morgeson \& Hofmann, 1999). We therefore use the term organizational affective tone, building upon George's (1990) seminal research on collective affect, to communicate our focus on descriptive norms that concern consistent, similar, and converging affect among organizational members. Organizational affective tone falls within the overarching construct space of collective affect (Menges \& Kilduff, 2015) and shares commonalities with the relatively broader and multifaceted concepts of emotional culture (Barsade \& O'Neill, 2014) and affect climate (Parke \& Seo, In Press). These concepts, which include descriptive norms, also incorporate prescriptive norms regarding the emotions that employees should experience and express at work. Organizational affective tone, in contrast, does not reflect organizational members' beliefs regarding how they should feel or express their emotions; it reflects how the members of an organization actually feel.

What leads to converging feelings among the members of a large collective? To develop theory about the origins and effects of organizational affective tone, we draw upon an open systems perspective (e.g., Katz \& Kahn, 1978; Thompson, 1967), which views organizations as systems that convert inputs (e.g., raw materials) into valuable outputs (e.g., finished products) through some process of transformation (e.g., a manufacturing process). Inside an organizational system are multiple subsystems, such as divisions, functions, and norms-including, we suggest, descriptive norms regarding affect. As parts of a system with an overarching objective (i.e., creating value through a transformation process), subsystems are inherently interdependent. Uniting the multiple interdependent parts of an organization is a common logic that stems from the organization's overarching purpose and objectives (Katz \& Kahn, 1978). 
Which specific objectives a given organization pursues is defined by its domain (Levine \& White, 1961)—“the territory an organization stakes out for itself with respect to products, services, and market served" (Daft, 2006: 138). An organization's domain reflects senior leaders' strategic choices regarding which industries to compete in and which specific elements of the value chain within those industries to occupy. Consider, for example, the STIHL Group-a company that designs and manufactures power tools (e.g., chainsaws). Leaders' strategic choices have defined STIHL's domain as encompassing the production of chainsaws through design and manufacturing. Retailing, however, falls outside of STIHL's domain. Rather than forward integrate and sell directly to end consumers, STIHL distributes its products (i.e., the outputs of its transformation process) through a network of approved dealers who maintain their own retail outlets. Understanding the boundaries of an organization's domain is important because the domain determines the sources of an organization's inputs (e.g., parts or components manufacturers, metal and plastic suppliers) and the recipients of an organization's outputs (e.g., dealers, retailers, consumers) (Levine \& White, 1961). A signature of an open systems approach is the idea that the organization is itself a subsystem that is nested within an overarching external environment. Because the components of any system are interdependent, an organization both influences and is influenced by its external environment. An open systems perspective suggests that similar domains, which have similar core activities and external constituencies, lead organizations to internally function in similar ways (Katz \& Kahn, 1978; Thompson, 1967).

In examining the implications of an organization's connections with its external environment for its internal functioning, scholars across several disciplines (Hill, 1977; Katz \& Kahn, 1978; Lovelock, 1983; Mills \& Moberg, 1982; Thompson, 1967) make an important distinction between activities in consumer-centric industries - that is, activities that envelop or 
involve the end user — and activities in industries that are separate from or buffered from the end user. Activities in consumer-centric industries, such as customer service and retail, are those in which the individual consumer is an active and essential participant in the transformation process that converts inputs into outputs. These can be contrasted with activities that occur earlier in the value chain, such as manufacturing and production or wholesale trade. In these activities, the consumer plays a more peripheral role and only indirectly receives — through one or more other companies - the outputs of the transformation process. Importantly, an organization's domain can comprise many different activities; thus, any single organization may engage in some activities that are consumer-centric and some that are not.

The degree to which an organization's domain comprises consumer-centric activity likely has important implications for its overarching affective tone. A hallmark of consumer-centric activities is that value is created through the experience that a consumer or end user has when interacting with the organization (Lovelock, 2001; Verma, 2003). From an open systems perspective, the transformation process for a consumer-centric activity is such that the output is some change in the end user or consumer (Katz \& Kahn, 1978). For the vast majority of consumer-centric activities, business organizations seek to add value in the transformation process by creating positive affective experiences for consumers (e.g., delight) and avoiding or eliminating negative affective experiences (e.g., outrage) (Grandey, 2000; Oliver, Rust, \& Varki, 1997; Schneider \& Bowen, 1999; Verma, 2003). ${ }^{1}$ Positive affective experiences, especially activated ones like delight, enhance consumers' perceptions of the quality of the interaction with the organization and contribute to customer loyalty (Pugh, 2001; Schneider \& Bowen, 1999). Negative affective experiences, in contrast, not only have a detrimental impact on the individual

\footnotetext{
${ }^{1}$ This is not true for some consumer-centric activities, such as bill collection (Sutton, 1991), in which the consumer is not making an active choice to engage with the organization.
} 
consumer's relationship with the organization, but can also lead a consumer to speak poorly of the business with others (Schneider \& Bowen, 1999; Verma, 2003). For these reasons, theory and research in service marketing and retailing suggest that employees' moods and emotions are among "the few antecedent states impacting all service encounters" (Kelley \& Hoffman, 1997: 407, italics in original; see also Knowles, Grove, \& Pickett, 1993). Affect is thus recognized as an intrinsic part of a consumer-centric organization's core transformation process. In contrast, for organizations whose activities are concentrated further up the value chain, and are buffered from the consumer or end user, affect is more often portrayed as something that disrupts or hinders the effective performance of tasks (Ashforth \& Humphrey, 1995; Mumby \& Putnam, 1992; Seo \& Barrett, 2007)_-“to obtain the best results, emotions must be kept out” (Damasio, 1994: 171).

It is likely that the more an organization's domain comprises consumer-centric activities, the more positive and less negative the organization's affective tone is. When an organization's domain consists mostly of consumer-centric activities, its primary mode of creating value inherently involves creating positive affective experiences and avoiding negative affective experiences. Because the subsystems of an organization are interdependent and rooted in the dominant logic that underlies the organization's core transformation process (Katz \& Kahn, 1978), the premium placed on these affective experiences is not just localized to those organizational subsystems that interact directly with consumers. Even those subsystems that are not involved in direct interactions with consumers should, the more the organization's domain comprises consumer-centric activity, exhibit a common affective tone that is relatively more positive and less negative.

Note that we are not suggesting here that this organizational affective tone eliminates the potential for sub-unit norms. There is, indeed, ample theoretical and empirical precedence for the 
emergence of sub-unit norms in organizations-particularly those that emerge around occupational or functional units (i.e., Dierdorff, \& Morgeson, 2013; Schauebroeck, Ganster, \& Jones, 1998; Schneider, 1987; Schneider, Goldstein, \& Smith, 1995). In accordance with prior theory, what we are suggesting is that a global, organizational affective tone co-exists with and transcends any local, sub-unit norms that may emerge. To borrow and adapt an illustrative example from Schneider (1987), consider two organizations-Boeing and Southwest Airlineswith activities in different segments of the airline industry value chain. What we propose is that, regardless of functional sub-unit, an employee at Southwest Airlines-in which consumercentric activities are prominent and prevalent—would likely report a more positive and less negative affective tone than would an employee at Boeing. For example, consider someone who works in an accounting function. Although an accountant working for Southwest Airlines has some competencies and perspectives that are similar to a Boeing accountant, the two likely differ in their view of the centrality and importance of affect to the core purpose of their company's work. The primary way that organizations create value - and, specifically, the degree to which an organization engages in consumer-centric activity-influences not just front-line service providers' experiences, but also other organizational subsystems (Katz \& Kahn, 1978).

Given the importance of this assumption that a meaningful organizational affective tone co-exists with and transcends any occupational sub-unit norms regarding affect, we empirically examine it prior to testing our prediction regarding the connection between organizational domain and organizational affective tone.

Hypothesis 1: The more an organization's domain comprises consumer-centric activity, the (a) more positive and (b) less negative its affective tone. 
Hypothesis 1 focuses specifically on organizational members' consistent affect. Theory and research on emotional labor suggest, however, that employees' external expressions of emotion often deviate from their internal experiences and, further, that how people manage this dissonance has implications for workforce strain (Grandey \& Gabriel, 2015). The corpus of existing empirical findings is mixed regarding the degree to which norms regarding emotional expression —in which employees are expected to express a particular range of feelings-differ for those engaged in consumer-centric work, compared to those whose work is buffered from the end user. Although classic theory and research (e.g., Hochschild, 1983) highlighted "people work" as inherently comprising rules regarding emotional expression, more recent thinking suggests that many kinds of work require employees to govern their expressions-whether to neutralize their expressions of emotion or to display positive or negative feelings (e.g., Grandey, Diefendorff, \& Rupp, 2015; Mann, 1999). Moreover, theory and research suggest that one highly effective way that employees often meet expectations regarding their emotional expression is to alter their true feeling states - that is, to engage in deep acting (Grandey, 2000). Nonetheless, research does suggest that collectives vary in norms governing emotional expression (Diefendorff, Erickson, Grandey, \& Dahling, 2011), which presents a potential confound for Hypothesis 1 . To address this issue, we control in our empirical study for the degree to which employees perceive the organization to support the open expression of employees' veridical feelings. This focuses our analysis specifically on organizational affective tone-the consistent affect that employees authentically feel—rather than on the outward expression of feeling states.

\section{Embedding Mechanisms: Personnel Practices and Organizational Structure}

We now introduce a meso perspective to explain how the more distal and macro concept of an organization's domain connects to the more micro concept of affective tone. Our 
explanation highlights the likely role of leaders' choices regarding personnel practices and organizational structure — organizational elements that theory and research suggest play an important role in disseminating norms across organizations (Schein, 2010; Schneider, Ehrhart, \& Macey, 2013), but that have not been related to organizational affective tone. As we describe in detail below, personnel practices and organizational design shape organizational norms about affect in two primary ways. First, these mechanisms shape the composition of an organization's workforce by determining the kinds of people who are attracted to, selected by, and remain in an organization (George, 1990; Schneider, 1987). Second, these mechanisms act as overarching organizational practices that directly influence the affect that organizational members have, serving as a common overarching stimulus to which organizational members are exposed. These mechanisms for embedding organizational affective tone differ from micro mechanisms advanced in prior theory and research, thus offering a new and unique meso perspective on affect in organizations.

Emotion-focused personnel practices. Organizational leaders use personnel practices to maximize the fit of role occupants to both the demands of specific jobs and the broader norms and values of the organization (Chatman, 1991). Personnel practices likely embed organizational affective tone by determining the kinds of people who are attracted to, selected by, promoted to leadership positions in, and remain a part of organizations (George, 1990; Schneider, 1987). Scholars (e.g., Arvey, Renz, \& Watson, 1998; Rafaeli \& Sutton, 1987) have suggested that one way for organizations to cultivate the emotional capacity necessary for the effective execution of consumer-centric activities is by recruiting and selecting individuals who have appropriate emotional dispositions and skills. Because of the centrality of emotion to their core transformation process, and an associated view of emotion as valuable, organizations with high 
levels of consumer-centric activities are especially likely to adopt and use personnel practices for recruitment, selection, and promotion that consider a role occupant's inclination to experience positive and manage negative feelings. We refer to these practices as emotion-focused personnel practices. In organizations with domains composed of low levels of consumer-centric activities, emotion is a more peripheral part of the transformation process. Accordingly, if emotion is viewed as tangential to the organization's mode of value creation, personnel practices are unlikely to consider individuals' emotional tendencies (Mumby \& Putnam, 1992). Differences in affective tone that more distally stem from the degree to which an organization's domain comprises consumer-centric activity may thus be more proximally embedded by the kinds of personnel practices that an organization uses.

\section{Hypothesis 2: The use of emotion-focused personnel practices partially mediates} the relationship between consumer-centric activity and organizational affective tone.

Organizational design. Organizational design is an important tool that senior leaders use to implement strategy (Chandler, 1962). Organizational design choices may also serve to embed affective norms that support an organization's domain of activity. Organizational designnamely, formalization and centralization-governs the flow of work among subsystems; and, how the flow of work is governed communicates and reinforces norms for those currently in an organization and for those who consider joining an organization (Schaubroeck, Ganster, \& Jones, 1998; Schein, 2010; Schneider et al., 2013). Formalization reflects the degree to which work processes are codified in written rules and standards (Hage \& Aiken, 1967; Pugh, Hickson, Hinings, \& Turner, 1968). Highly formalized organizations have prescribed and documented rules for employees' work, while less formalized organizations have fewer written guidelines to 
govern employee behavior. Centralization reflects the degree to which decision-making is concentrated in an organization (Hage \& Aiken, 1967; Pugh et al., 1968). In a highly centralized organization, subordinates seek the approval of and defer to superiors when making decisions. In a relatively decentralized organization, subordinates retain discretion over making decisions. According to open systems theory, leaders use formalization and centralization to stabilize the transformation process and enable an organization to fulfill its objectives (Katz \& Kahn, 1978).

Consumer-centric activity, compared to activity that is buffered from consumers, presents distinct challenges for organizations, which likely leads them to rely less on formalization and centralization for managing the flow of work (Katz \& Kahn, 1978). Scholars describe consumercentric activity, in particular, as being high in heterogeneity and inseparability (Schneider \& White, 2004). Heterogeneity refers to a high degree of variability in inputs during the transformation process. Consumer-centric activity is inherently an interactive process between employees and consumers (e.g., customers, clients) (Katz \& Kahn, 1978). Effective task performance depends not just on what employees do, but also on what customers do and how employees then react to these customer behaviors (Côté, 2005; Schneider \& Bowen, 1995). Because of this dynamic interplay, every encounter is different (Lovelock, 2001). Inseparability refers to the fact that some of the value created in consumer-centric activity is produced and consumed simultaneously — there is little separation between the activities of the organization in creating value and the customer's consumption of the value (Schneider \& White, 2004). Inseparability makes time a uniquely difficult challenge for organizations with a domain in which consumer-centric activities are prevalent; there is limited time to inspect and revise the quality of the organization's output. The transformation process in organizations highly engaged 
in consumer-centric activities is thus characterized by the need to not only create positive experiences for consumers, but to do so despite heterogeneity and inseparability.

Facing heterogeneity, inseparability, and the need to create a positive experience, formalization and centralization are less attractive structural choices for an organization to the extent that it is engaged in consumer-focused activities. With significant variability in inputs (i.e., consumers), it is relatively more difficult to document and formalize the requirements of every work encounter in detailed rules and regulations. With the consumption of value entwined with the production of value, it is relatively costlier to take the time to seek out and defer to the preferences of superiors as delays can compromise the customer experience. Note that we are not suggesting that organizations engaged in consumer-focused activity completely eschew the bureaucratic form. Classic theory and research (e.g., Hochschild, 1983) details how bureaucratic principles are used in consumer-focused activity. However, the degree of formalization and centralization is likely less in a retail store, for example, than it is in a manufacturing plant.

Formalization and centralization rationalize and depersonalize the work environment, clearly delineating how a role should be performed and to whom one must defer (Weber, 1978). With a purpose of reducing ambiguity and enhancing predictability (Hage \& Aiken, 1967; Jansen, Van Den Bosch, \& Volberda, 2006), formalization and centralization in the ideal bureaucratic form were meant to minimize the intrusion of employees' idiosyncrasies into organizational functioning. In the ideal bureaucratic form, one could argue that these structural elements would facilitate a relatively more positive and less negative affective tone because they reduce role ambiguity and role conflict, which arise when workers lack clarity on the expected behaviors in their role and/or hold a different understanding than others about their role (Katz \& Kahn, 1978). A large body of empirical research has shown that the confusion inherent to role 
ambiguity and role conflict is generally negatively related to favorable attitudes that employees hold about their work (e.g., Jackson \& Schuler, 1985) and positively related to unpleasant feelings like anxiety and anger (e.g., Rodell \& Judge, 2009).

As Weber noted, however, the features of a bureaucracy over time become an "iron cage" that does not just neutralize emotions, which are viewed as the antithesis of rationality and efficiency in the bureaucratic form (Ashforth \& Humphrey, 1995). Rather, formalization and centralization concentrate control in the workplace in a relatively small number of people whose goals center on efficiency and the pursuit of organizational goals_-perhaps to the detriment of the quality of workers' experiences. Because both of these design elements concentrate decisionmaking in a limited set of roles and in standardized procedures, they strip employees of autonomy. As research on job design has shown, by reducing employees' autonomy, centralization and formalization both generally lead to less positive and more negative views of and reactions to the workplace (Oldham \& Hackman, 1981).

In addition to influencing affective tone by directly shaping affective experiences, theorists have also suggested that organizational design choices may influence organizations by altering the composition of the workforce. Most relevant for understanding the emergence of organizational affective tone, Schaubroeck et al. (1998) suggested that people with different affective dispositions may prefer different organizational structures. Specifically, Schaubroeck et al. (1998) argued that those high in extraversion (akin to trait positive affectivity) prefer structures characterized by low formalization and centralization and those high in neuroticism (akin to trait negative affectivity) prefer structures characterized by high formalization and centralization. If this is indeed the case, then organizational design choices could also influence 
organizational affective tone by creating the conditions which would determine the kinds of people who would be attracted to and decide to remain in an organization.

Organizational centralization and formalization thus likely serve to create a relatively less positive and more negative organizational affective tone. Differences in affective tone that distally stem from the degree to which an organization's domain comprises consumer-centric activities may be more proximally embedded by formalization and centralization.

Hypothesis 3: Formalization partially mediates the relationship between consumer-focused activity and organizational affective tone.

Hypothesis 4: Centralization partially mediates the relationship between consumer-focused activity and organizational affective tone.

\section{Organizational Affective Tone and Workforce Strain}

Research suggests that people who work in the same organizational unit, group, or team, often show similar levels of workforce strain. Manifesting in employee exhaustion and withdrawal behaviors like absenteeism, high workforce strain is a consequential outcome that is extremely costly for organizations (Côté, 2005). According to the job demands-resources model (Demerouti et al., 2001), systematic levels of strain in a collective are due to the fact that group members face similar contextual demands (e.g., workload, time pressure, physical constraints) and possess similar resources (e.g., training, supportive programs, job security) as a function of their unit membership. That is, above and beyond idiosyncratic individual characteristics that contribute to within-group variation in individual strain, members' exposure to a common set of contextual factors contributes to common and systematic collective workforce strain.

Research findings provide clues that organizational affective tone may act as such a contextual factor that either heightens or ameliorates workforce strain (Barsade \& Knight, 2015; 
Barsade \& O’Neill, 2014; George, 1990; Mason \& Griffin, 2003; O’Neill \& Rothbard, In Press). Specifically, positive affective tone may act as a resource, buffering against typical workplace stressors (Fredrickson, 1998; Lyubomirsky King, \& Diener, 2005) and reducing workforce strain. In contrast, negative affective tone may act as a demand, exacerbating the effects of typical workplace stressors and increasing workforce strain (Bono, Glomb, Shen, Kim, \& Koch, 2013; Côté, 2005). Several empirical studies have provided evidence that is consistent with this idea. Barsade and O’Neill (2014) found that a culture of companionate love-comprising a specific set of discrete emotional norms - in the facilities of a long-term health care organization was associated with lower employee absenteeism. Similarly, Mason and Griffin (2003) found a negative relationship between positive affective tone and absenteeism in a survey study of government workgroups. And, in her initial work on affective tone, George (1990) found a positive relationship between negative affective tone and employee absenteeism in department stores. We extend this line of research by examining the effects of positive and negative affective tone on workforce strain at the organizational level. Consistent with our expectation that affective tone fulfills similar functions in large collectives as it does in small groups and teams (i.e., Morgeson \& Hofmann, 1999), we expect the same pattern as in prior research, such that positive affective tone lowers workforce strain whereas negative affective tone heightens workforce strain.

Hypothesis 5: Organizational affective tone relates to workforce strain such that (a) positive affective tone decreases workforce strain and (b) negative affective tone increases workforce strain. 


\section{METHOD}

\section{Research Setting and Procedure}

The data for this study were collected as part of a large benchmarking project involving German firms that operated in a range of industries and had up to 5,000 employees. In exchange for participation in the research project, firms were offered a detailed report to use in comparing aspects of their human resource practices, norms, and organizational design with other firms. Firms were recruited using a targeted marketing campaign, which included print advertisements and direct mailings to organizations. Of 202 firms that initially signaled interest in the study and received detailed information about requirements of the study, 161 firms ultimately participated, yielding a firm-level response rate of approximately $80 \%$.

We collected survey data from six different sources within each firm. First, a representative from each firm's human resource function provided background information about the firm (e.g., age, size, firm activities), responded to survey items about the firm's use of personnel practices, and provided archival data regarding employee sick days (Human Resource Survey). Second, members of the firm's top management team responded to survey items asking about prior firm performance (Top Management Team Survey). Third, four different subsets of employees were randomly selected to provide responses to different sets of survey items. One group of employees provided ratings of positive and negative affective tone (Employee Survey A); a second group reported on beliefs about how openly employees could express emotions (Employee Survey B); a third group provided insight into aspects of the firm's design (i.e., centralization, formalization) (Employee Survey C); and, a fourth group responded to survey items about emotional exhaustion (Employee Survey D). Although it limited our ability to examine relationships among variables at the individual-level, our use of a split-sample design 
(Rousseau, 1985) was practically necessary to minimize the length of surveys that respondents completed and mitigates concerns of single source bias, which may inflate bivariate relationships among variables (Podsakoff, MacKenzie, Lee, \& Podsakoff, 2003).

The data collection procedure was standardized across all participating firms. A representative from the human resource function was identified within each firm. This person acted as the primary point of contact between the research team and the company. After the firm agreed to participate in the study, we emailed the point of contact a hyperlink to a web-based survey hosted by an independent IT company. The point of contact completed this initial survey, which collected background information about the firm. After completing this survey, the point of contact was instructed to send a pre-formulated e-mail to all employees of his or her firm, as well as to members of the top management team. The e-mail contained a short description and invitation to participate in the study, a statement emphasizing the confidentiality of participants' survey responses, and a hyperlink to the survey website. Upon clicking the hyperlink, a given employee was randomly assigned by the surveying software to one of the employee survey groups described above; top management team members were connected directly to their survey. Because some employees lacked access to a computer, we also provided printed surveys as necessary. Printed surveys were distributed with randomization into the employee survey groups and, upon completion, were processed by university research assistants.

\section{Sample}

The 161 participating firms had an average of 344 employees $(\mathrm{SD}=577.68)$. The firms were established companies, having operated for 44.60 years on average $(\mathrm{SD}=44.50)$. We received completed survey responses from 24,015 individuals. While they responded to separate sets of survey items, participants all provided the same demographic information. The employee 
sample was $66 \%$ male. Employees were 38.30 years old on average $(\mathrm{SD}=10.43)$ and had been with their firms for an average of 7.66 years $(\mathrm{SD}=7.99)$.

The median within-firm response rate was $65 \%$. Due to our randomization of employees into survey groups, there were roughly equal numbers of surveys completed for Employee Survey A $(\mathrm{N}=5,975), \mathrm{B}(\mathrm{N}=5,840), \mathrm{C}(\mathrm{N}=5,750)$, and $\mathrm{D}(\mathrm{N}=6,050)$. This yielded a withinfirm, per construct response rate of approximately $16 \%$ (i.e., roughly $16 \%$ of a firm's employees rated each construct). Because employees were randomly assigned to rate constructs, however, there is little concern that this systematically biased the scores for a particular construct; instead, the primary implication of any sampling error introduced by this procedure would be decreased power to detect organization level relationships (Nesterkin \& Ganster, 2015). This is unlikely to be a problem in our dataset, however, given the relatively large number of respondents (i.e., on average more than 30) per construct (Bliese, 1998).

The sample of top management team members differed from the employee sample in a few ways. We were able to collect top management team ratings of prior performance for 129 of the 161 firms in our sample. The firms for which we obtained no top management team data did not differ significantly from the other firms in our sample on any of the variables examined in the conceptual model. For the 129 firms that did provide top management team ratings, we received a total of 400 survey responses, for an average of 3 top management team members per firm $(\mathrm{SD}=2.39)$. The sample of top managers was predominantly male $(90.26 \%)$. Top managers were on average 45.22 years old $(\mathrm{SD}=8.18)$ and had been with their firms for an average of 11.13 years $(\mathrm{SD}=8.66)$. 


\section{Measures}

We used a double-blind translation-back-translation procedure, first translating any original English measures into German, then translating the German version into English, to ensure measure equivalence. The English versions of multi-item survey measures used to measure the constructs in our conceptual model are provided in the appendix. Unless otherwise noted below, participants used a 7-point Likert-type scale, ranging from $1=$ Strongly disagree to 7 = Strongly agree, to respond to survey items. Interitem reliability values (i.e., Cronbach's alpha) for multi-item scales computed at the firm level of analysis (Chen, Mathieu, \& Bliese, 2004) are provided along the diagonals in Table 1.

\section{Insert Table 1 about here}

Consumer-centric activity. The human resource point of contact for each firm provided in the Human Resource Survey information about the firm's activities across five categories of the Standard Industrial Classification (SIC) system: service; retail; wholesale trade; finance, insurance, and real estate; and production and manufacturing. Two of these categories—service and retail-are relatively high in consumer centricity, with the end consumer playing an active and essential role in the transformation process. The remaining three categories are relatively low in consumer centricity, such that the end consumer is not much involved in how the firm generates value through its transformation process. The human resource representative provided a percentage breakdown in response to the prompt "To what extent is your company active in...", assigning 100 possible percentage points across the five categories. We operationalized firm participation in consumer-centric activity as the sum of percentages in the service and retail categories. Values on this index ranged from zero to $100 \%$, with a mean of $56.93(\mathrm{SD}=46.08)$. 
To bolster our confidence in the human resource representative's reporting of consumercentric activity, we instructed two research assistants to independently review and rate the degree of consumer centricity in each firm's mode of value creation. Specifically, research assistants used information provided by each company about its activities and used a five-point scale to rate "the extent to which this company creates value through interactions with customers and consumers." The two research assistants agreed with one another in their ratings $\left(\right.$ Median $\mathrm{r}_{\mathrm{wg}}=$ 1.00). The combined research assistant rating correlated highly with our measure based on the human resource representative's classification of company activity across industries $(\mathrm{r}=0.80, p$ $<0.01$ ), providing convergent validity for our measure of consumer-centric activity. ${ }^{2}$

Organizational affective tone. Employees completing Employee Survey A responded to nine items drawn from the Job-Related Affective Well-Being Scale (Van Katwyk, Fox, Spector, \& Kelloway, 2000) that assessed their firm's affective tone. Service and retail scholars (e.g., Oliver et al., 1997; Schneider \& Bowen, 1999) suggest that high activation positive experiences (e.g., delight) create value in consumer-centric activities, while high activation negative experiences (e.g., outrage) destroy value. Accordingly, we measured positive affective tone by using five high activation and pleasant emotions (e.g., enthusiasm) and we measured negative affective tone with four high activation and unpleasant emotions (e.g., anger). Because we view affective tone as an organization-level phenomenon-that is, a construct that inherently lies at the firm level of analysis—we used a referent shift composition model (Chan, 1998) and survey items that targeted the firm-level (i.e., "the employees of this company"), aligning the measure with the theoretical level of analysis (Klein \& Kozlowski, 2000). Specifically, we asked

\footnotetext{
${ }^{2}$ We replicated the analyses we report below using the research assistants' coding as the operationalization of consumer-centric activity. Our findings are identical in the statistical significance and approximate magnitude of parameters, which is expected given the high correlation between the two measures of consumer-centric activity.
} 
respondents to indicate using a 5-point scale ranging from $1=$ Never to $5=$ Frequently if not always how often in the last six months the employees of their company had experienced these emotions.

To ensure the validity of our operationalization of these constructs using individual-level survey responses, we examined within-group homogeneity and between-group variance using the $r_{\mathrm{wg}(\mathrm{j})}$ index of interrater agreement and two versions of the intraclass correlation coefficient (Bliese, 2000). Whereas $r_{\mathrm{wg}(\mathrm{j})}$ provides an assessment of how much individual respondents within each firm provide similar ratings, ICC(1) takes into account between-group variance and ICC(2) assesses the reliability of the firm mean, which depends in part on the number of respondents per firm (Bliese, 2000). This package of indices provided support for using the mean of organization members' survey responses to operationalize both positive affective tone $[\operatorname{ICC}(1)=0.12, p<$ $0.01 ; \operatorname{ICC}(2)=0.84 ;$ Median $\left.r_{\mathrm{wg}(\mathrm{j})}=0.91\right]$ and negative affective tone $[\mathrm{ICC}(1)=0.12, p<0.01$; $\operatorname{ICC}(2)=0.83 ;$ Median $\left.r_{w g(j)}=0.89\right]$

Emotion-focused personnel practices. We developed a 6-item measure of emotionfocused personnel practices to assess the degree to which emotion plays a role in core human resource decisions (i.e., recruitment, selection, and promotion). The human resource representative for each firm responded to the items (Human Resource Survey), reporting on his/her firm's practices. A sample item is "In the selection process we specifically examine the job candidate's capacity for enthusiasm.”

Firm formalization. We measured firm formalization in Employee Survey $\mathrm{C}$ using five items derived from Pugh et al. (1968) and also frequently used in research on organizational design (e.g., Jansen et al., 2006; Schminke, Ambrose, \& Cropanzano, 2000; Schminke, Cropanzano, \& Rupp, 2002). As above, because formalization is an organization-level 
phenomenon, we used a referent shift composition model. A sample item is "For each situation you can think of, there is a written instruction." We operationalized formalization as the firmlevel mean of individual responses $\left[\operatorname{ICC}(1)=0.21, p<0.01 ; \operatorname{ICC}(2)=0.90 ;\right.$ Median $r_{\mathrm{wg}(\mathrm{j})}=$ 0.80].

Firm centralization. We measured firm centralization in Employee Survey C using items adapted from Hage and Aiken (1967) and frequently used in research on organizational structure and design (e.g., Jansen et al., 2006; Schminke et al., 2000, 2002). Participants responded to five items asking about the degree to which decision-making is centralized in their firm; a sample item is "Even for small things employees have to get the permission from a supervisor before they can take a final decision." We operationalized centralization as the firm-level mean of individual responses $\left[\operatorname{ICC}(1)=0.12, p<0.01 ; \operatorname{ICC}(2)=0.83 ; \operatorname{Median} r_{\mathrm{wg}(\mathrm{j})}=0.77\right]$.

Workforce strain. We measured workforce strain using two indicators, to reflect its physiological and psychological components and to capture the perspectives of multiple sources. First, we asked the human resource representative (Human Resource Survey) to report the frequency of employee absenteeism due to illness, asking "How many days on average have employees been sick since the beginning of this year?" Second, we measured employees' perspectives using four items drawn from the emotional exhaustion subscale of Maslach and Jackson's (1981) burnout measure. Emotional exhaustion is an individual-level phenomenon; however, we are interested in understanding systematic organization level variance in exhaustion. Accordingly, like Demerouti et al. (2001), we used a direct consensus composition model (Chan, 1998) with survey items targeting the individual. Respondents to Employee Survey D used a 7-point scale, ranging from $1=$ Once a year or less often to $7=$ More than once $a$ day to indicate how frequently they experienced emotional exhaustion. A sample item is "I feel 
burned out from my work." There was systematic organization-level variance in emotional exhaustion $\left[\operatorname{ICC}(1)=0.04, p<0.01 ; \operatorname{ICC}(2)=0.60 ;\right.$ Median $\left.r_{\mathrm{wg}(\mathrm{j})}=0.80\right]$; so, we used the firmlevel mean of individual responses.

\section{Confirmatory Factor Analysis}

Because we adapted some scales to refer to the firm level of analysis and also developed new items to measure emotion-focused practices, we used confirmatory factor analysis to verify the validity of our expected measurement model at the firm level of analysis. Specifically, we fit a model for constructs measured by multi-item survey measures, specifying all hypothesized items as loading on their respective factors, and allowed latent factors to covary. The specified measurement model was an acceptable fit for the data $\left(\chi_{362}^{2}=814.99, p<0.01 ; \mathrm{CFI}=0.90\right.$; RMSEA $=0.09 ;$ SRMR $=0.12$ ) and all items exhibited expected loadings on their factors. To provide evidence for the discriminant validity of our survey measures of positive and negative affective tone, we fit a model with all items measuring affective tone loading on a single factor.

The fit of this model $\left(\chi_{367}^{2}=1008.77, p<0.01 ; \mathrm{CFI}=0.85\right.$; RMSEA $=0.11$; SRMR $\left.=0.12\right)$ was significantly worse than a model specifying separate latent variables for positive and negative affective tone $\left(\Delta \chi^{2}{ }_{5}=193.78, p<0.01\right)$.

\section{Control Variables}

Economic data (e.g., US Census Bureau, 2016) and prior organizational research (e.g., Child, 1973; Pugh, Hickson, Hinings, \& Turner, 1969) suggest that firms high in consumer centric activity may on average be smaller, younger, and less unionized than firms low in consumer centric activity. Research (e.g., Jackson, Schuler, \& Rivero, 1989; Kimberly, 1976; Sine, Mitsuhashi, \& Kirsch, 2006) has shown that these organizational characteristics covary with the mechanisms — organizational design and personnel practices - that we posit connect 
consumer centric activity to organizational affective tone. We thus controlled in our analyses predicting these mechanisms and affective tone for the log of firm size (in number of employees), firm age (in years), and the percent of employees represented by a union. The human resources representative provided each of these variables.

We also included a control for the degree to which employees perceive norms supporting the open expression of employees' authentic feelings. This is an important variable to include in our models because our measure of organizational affective tone solicits employees' shared perceptions of the feelings that are typically experienced by organization members. If organization members do not express the emotions that they truly experience, however, our measure of affective tone may not truly capture converging affective experiences. Our use of a control for norms regarding the open expression of emotion is useful therefore to focus specifically on affective experience, rather than on display rules regarding emotion (Diefendorff et al., 2011; Grandey \& Gabriel, 2015). We measured organizational norms regarding the open expression of emotion using a four-item measure adapted from Diefendorff, Croyle, and Gosserand (2005) (Employee Survey B). A sample item is "Employees in our company are supposed to show their emotions just as they experience them.” There was systematic organization-level variance in employees' perceptions $[\mathrm{ICC}(1)=0.06, p<0.01 ; \operatorname{ICC}(2)=0.68$; Median $\left.r_{\mathrm{wg}(\mathrm{j})}=0.79\right]$; so, we used the firm-level mean of individual responses.

In testing our predictions regarding the relationship between organizational affective tone and workforce strain, we included three additional control variables. We controlled for the firmlevel mean of employees' self-reported age (in years) because prior research (e.g., $\mathrm{Ng} \mathrm{\&}$ Feldman, 2008) has shown significant relationships between age and absenteeism due to sickness. We also included two control variables to provide evidence that the relationship we 
observe between affective tone and workforce strain is not spuriously a function of past workforce strain or organizational performance (e.g., Schneider, Hanges, Smith, \& Salvaggio, 2003). Specifically, we controlled for the average number of employee sick days in the year prior to the focal study period, as reported by the human resources representative, and for top managers' ratings of firm performance in the year prior to the focal study period. Top managers used a 7-point scale $(1=$ Much worse to $7=$ Much better $)$ to rate company performance on six different facets (e.g., efficiency, financial performance) during the one year period preceding the focal study timeframe, as follows: "Compared to other companies in your industries, rate your company performance in..." Top managers showed within-group agreement and between-firm variation $\left[\operatorname{ICC}(1)=0.35, p<0.01 ; \operatorname{ICC}(2)=0.61 ;\right.$ Median $\left.r_{\mathrm{wg}(\mathrm{j})}=0.96\right)$; so, we used the firm mean across top managers' responses to operationalize prior performance.

Recognizing that the inclusion of control variables has the potential to obscure meaningful findings (e.g., Becker, 2005; Carlson \&Wu, 2012), we report the results of hypothesis tests both with the aforementioned control variables and without them. Our findings are substantively identical.

\section{RESULTS}

\section{Organizational and Occupational Variance Decomposition Analysis}

A fundamental assumption underlying our theoretical model is that organizations have an overarching consistent affective tone that transcends organizational subunits. The intraclass correlations and measures of within-organization agreement reported above are evidence for this. Yet, these indices could also reflect a higher proportion of consumer-focused occupations (e.g., customer service representatives, salespeople) in some firms than in others. To confirm that firms do vary in affective tone at the organizational level, and not just at the occupational level, 
we conducted a variance decomposition analysis. Specifically, we fit an unconditional random coefficient model predicting individual perceptions of organizational affective tone with two random intercept terms — one for an individual's firm and one for an individual's occupation. All survey respondents indicated their primary functional area within the firm using a set of 17 categories. ${ }^{3}$ Including these two random intercept terms enabled estimating the proportion of variance in affective tone attributable to firm and occupation, respectively.

The results of these analyses indicated that $14 \%$ of the variance in positive affective tone was due to organizational membership and about $2 \%$ of the variance in positive affective tone was due to occupation. Similarly, we found that $13 \%$ of the variance in negative affective tone was at the organization level and $1 \%$ of the variance in negative affective tone was at the occupation level. These results provide additional support for the basic assumption underlying our model that people who work in a given organization-regardless of their specific occupation—share common perceptions of the organization's overarching affective context. Customer service employees of a firm perceive their firm's affective tone in a way that is relatively similar to the perceptions of finance or accounting employees.

These results do not indicate that there is no difference in affective tone at lower levels of analysis. Affective tone may — and, indeed, likely does_-vary at a sub-unit level. Such localized affective tone co-exists, however, with a more generalized affective tone at the organizational level (Zohar \& Luria, 2005). Notably, our survey items, which targeted the organization level, were not designed to measure sub-unit affective tone. The results of these variance

\footnotetext{
${ }^{3}$ The functional areas, with percent of sample in parentheses, were: Assistant to the management (1.9); Internal support and service (1.1); Customer service, technical support (5.1); Facilities management (1.6); Finance and accounting (4.6); Human resources (3.8); Information technology (5.3); Logistics, warehouse (4.6); Management (0.9); Marketing, sales (17.5); Medical laboratory (0.1); Medical services (1.6); Patient care (3.5); Production, manufacturing, quality control (22.1); Purchasing (1.7); Research and development (4.6); Other (10.8). Approximately $9.3 \%$ did not provide their functional area.
} 
decomposition analyses show, however, that above and beyond any local agreement among unit members in their perceptions of organizational affective tone, there is a meaningful, consistent overarching organization-level affective tone that employees across sub-units perceive, in line with our conceptualization.

\section{Tests of Hypotheses}

We used two analytical approaches to test our hypotheses, with all variables at the organization level of analysis. We first used a series of OLS regression models to test our predictions while also accounting for control variables. Accounting for the effects of these control variables is particularly important given the cross-sectional nature of our dataset. A primary weakness, however, of using a series of OLS regression models is that this provides only a piecemeal examination of our conceptual model. Accordingly, we also used path analysis to provide a holistic test of our conceptual model and predictions. Because of the need to have a favorable ratio of observations to parameter estimates in path analysis (Kline, 2011), we excluded control variables from this analysis. These two approaches are thus complementarythe OLS results address concerns regarding alternative explanations for our findings and the path analysis results address questions about the veracity of the conceptual model as a gestalt. Due to large differences in the original scale of different variables in our analyses (e.g., consumer centric activity is on a scale of 0 to 100 , organizational affective tone is on a scale of 1 to 5), we report standardized parameter estimates.

Insert Tables 2 and 3 about here

Results of OLS regression analyses. Tables 2 and 3 present the results of regression analyses used to examine the antecedents of positive and negative affective tone. Hypothesis 1 
predicted that the more a firm participates in consumer-centric activity, the (a) more positive and (b) less negative the firm's affective tone. As seen in Models 2 and 5 of Table 2, consumercentric activity was positively associated with positive affective tone $(\beta=0.24, p<0.01)$ and negatively related to negative affective tone $(\beta=-0.17, p=0.01)$. Consumer-centric activity explained $5 \%$ of the variance in positive affective tone and $3 \%$ of the variance in negative affective tone, above and beyond the controls. Hypothesis 1 was supported.

Hypothesis 2 predicted that the use of emotion-focused human resource practices partially mediates the relationship between consumer-centric activity and affective tone. To test this hypothesis, we examined the indirect effects of consumer-centric activity on positive and negative affective tone, respectively, through emotion-focused personnel practices. In calculating the significance of indirect effects, we used bootstrapped standard errors based on 10,000 draws (Mackinnon \& Fairchild, 2009). Model 2 of Table 3 presents the results of analyses regressing emotion-focused human resource practices on consumer-centric activity. Consistent with Hypothesis 2, consumer-centric activity was positively related to the use of emotion-focused personnel practices $(\beta=0.18, p=0.04)$. Further, as shown in Model 3 of Table 2, the use of emotion-focused personnel practices was positively related to positive affective tone $(\beta=0.14, p$ $=0.01)$. Although in the predicted direction, the relationship between emotion-focused personnel practices and negative affective tone was not significant (Model 6 of Table $2, \beta=-0.08, p=$ 0.18). The indirect effect of consumer-centric activity on positive affective tone, through emotion-focused personnel practices, was positive and significant (Est. $=0.02, \mathrm{SE}=0.01,95 \%$ C.I. $=0.00,0.06)$. The indirect effect of consumer-centric activity on negative affective tone, through emotion-focused personnel practices, was negative but not significant $($ Est. $=-0.01, \mathrm{SE}=$ 0.01, 95\% C.I. $=-0.04,0.00)$. Together, these results support Hypothesis 2 with respect to 
positive affective tone, but not negative affective tone, suggesting that although emotion-focused personnel practices may facilitate a positive affective tone, they may not inhibit the development of a negative affective tone.

Hypothesis 3 predicted that formalization partially mediates the relationship between consumer-centric activity and affective tone. We followed the same process used to test Hypothesis 2 in testing Hypothesis 3. As shown in Model 4 of Table 3, consumer-centric activity was not significantly related to formalization $(\beta=-0.09, p=0.31)$, and formalization was not significantly related to either positive affective tone $(\beta=0.08, p=0.14)$ or negative affective tone $(\beta=-0.08, p=0.19)$. The indirect effects of consumer-centric activity on positive affective tone $($ Est. $=-0.01, \mathrm{SE}=0.01,95 \%$ C.I. $=-0.03,0.01)$ and negative affective tone $($ Est. $=0.01, \mathrm{SE}$ $=0.01,95 \%$ C.I. $=-0.01,0.03)$, through formalization, were not significant. Hypothesis 3 was not supported.

Hypothesis 4 predicted that centralization partially mediates the relationship between consumer-centric activity and affective tone. Again, we followed the process described above to test Hypothesis 4. First, as shown in Model 6 of Table 3, consumer-centric activity was negatively related to centralization $(\beta=-0.16, p=0.01)$. Second, as shown in Table 2, centralization was negatively related to positive affective tone (Model 3, $\beta=-0.51, p<0.01)$ and positively related to negative affective tone (Model $6, \beta=0.44, p<0.01$ ). Third, the indirect effect of consumer-centric activity on positive affective tone, through centralization, was positive and significant $($ Est. $=0.08, \mathrm{SE}=0.04,95 \%$ C.I. $=0.01,0.18)$. Furthermore, the indirect effect of consumer-centric activity on negative affective tone, through centralization, was negative and significant $($ Est. $=-0.07, \mathrm{SE}=0.04,95 \%$ C.I. $=-0.15,-0.01)$. Hypothesis 4 was supported. 
Together, the three embedding mechanisms explained $14 \%$ of the variance in positive affective tone and $9 \%$ of the variance in negative affective tone, above and beyond the controls and consumer-centric activity. Further, the inclusion of the three embedding mechanisms reduced the magnitude of the relationship between consumer-centric activity and affective tone, lending credence to the idea that these mechanisms partially mediate the effects of consumercentric activity on affective tone.

\section{Insert Table 4 here}

We proposed in Hypothesis 5 that (a) positive organizational affective tone decreases workforce strain and (b) negative organizational affective tone increases it. Table 4 presents the results of regression analyses used to test Hypothesis 5 for employee exhaustion (Model 2) and employee sick days (Model 4). ${ }^{4}$ As shown in Model 2, positive and negative affective tone together explained an additional $9 \%$ of the variance in emotional exhaustion, above and beyond the control variables. Negative affective tone was positively related to employee exhaustion $(\beta=$ 0.42, $p<0.01$ ), providing partial support for Hypothesis $5 .{ }^{5}$ As Model 4 of Table 4 shows, the two affective tone variables explained an additional $1 \%$ of the variance in employee sick days, beyond the controls. Positive affective tone was negatively related to employee sick days $(\beta=-$ 0.23, $p=0.08$ ). These results partially support Hypothesis 5 .

Insert Figure 2 here

\footnotetext{
${ }^{4}$ Some of the predictors in these models have high bivariate correlations. Accordingly, we examined variance inflation factors (VIF) to determine the severity of multicollinearity. All VIF values were less than 4.

${ }^{5}$ As a robustness check, we also used multilevel modeling, predicting individual responses to emotional exhaustion, nested within firm, as an intercepts-as-outcomes model. The results were nearly identical to those reported here in magnitude, direction, and significance.
} 
Results of path analysis. We next used path analysis, fitting the model as depicted in Figure 2, to conduct a single holistic test of the conceptual model underlying our specific hypotheses. In addition to paths specified in our hypotheses, this model includes two additional covariance terms - one between formalization and centralization and a second between positive affective tone and negative affective tone. These covariance terms are included to capture shared variance stemming from the fact that members of Employee Survey C provided ratings of both dimensions of organizational structure and members of Employee Survey A provided ratings of both dimensions of organizational affective tone. We used bootstrapped standard errors with 10,000 draws to conduct two-tailed tests of statistical significance for path coefficients and indirect effects.

The hypothesized model presented in Figure 2 fit the data well $\left(\chi^{2}{ }_{13}=15.34, p=0.29\right.$; $\mathrm{CFI}=0.99 ; \mathrm{TLI}=0.99 ; \mathrm{RMSEA}=0.03 ; \mathrm{SRMR}=0.04)$ and the pattern of standardized path coefficients mirrored in significance the aforementioned results of OLS regressions including control variables. Consumer centricity was positively related to the use of emotion-focused personnel practices $(\beta=0.19, p=0.02)$ and negatively related to centralization $(\beta=-0.27, p<$ 0.01). The use of emotion-focused personnel practices was positively related to positive affective tone $(\beta=0.19, p<0.01)$ and negatively related to negative affective tone $(\beta=-0.13, p=0.02)$. Centralization was negatively related to positive affective tone $(\beta=-0.74, p<0.01)$ and positively related to negative affective tone $(\beta=0.69, p<0.01)$. Indirect effects analyses were also consistent with the OLS results. As above, there was support for centralization as a mechanism connecting consumer centricity to positive affective tone $(\beta=0.20, p<0.01)$ and negative affective tone $(\beta=-0.19, p<0.01)$. And there was support for emotion-focused personnel practices as a mechanism connecting consumer centricity to positive affective tone ( $\beta$ 
$=0.04, p=0.05)$. Consistent with our regression results, formalization did not play a meaningful role as an embedding mechanism for organizational affective tone. These aspects of organizational structure and personnel practices explained $54 \%$ of the variance in positive affective tone and $47 \%$ of the variance in negative affective tone. Positive affective tone was negatively related to company sick days $(\beta=-0.21, p=0.05)$ and negative affective tone was positively related to emotional exhaustion $(\beta=0.49, p<0.01)$. The model explained $12 \%$ of the variance in sick days and $29 \%$ of the variance in emotional exhaustion.

\section{Post-Hoc Exploratory Analyses}

Our findings above provided partial support for our predictions regarding a main effect relationship between organizational affective tone and workforce strain. In light of the relatively small main effects that we observed, and considering empirical findings suggesting that resources play a particularly important role in highly stressful contexts (e.g., Bakker, Demerouti, \& Euwema, 2005), we wondered whether an organization's domain might itself play a moderating role, shaping the extent to which affective tone heightens or decreases strain. If the degree to which an organization engages in consumer-centric activity is itself a stressor, perhaps the relationship between organizational affective tone and workforce strain is contingent upon consumer-centric activity.

To examine this question, we refit the models presented in Models 2 and 4 in Table 4 using unstandardized, but mean-centered predictor variables and added the interactions between affective tone and consumer-centric activity. The interactions explained significant variance, above and beyond the control variables and direct effects, in employee exhaustion (12\%) and employee sick days (3\%). There were two significant interactions between affective tone and consumer-centric activity. The relationship between positive affective tone and employee 
exhaustion was moderated by consumer-centric activity $(\mathrm{B}=0.16, p<0.05)$, as was the relationship between negative affective tone and employee sick days $(\mathrm{B}=-0.93, p<0.05)$.

Insert Figure 3 and Figure 4 about here

To better understand the nature of these interactions, we conducted simple slopes analysis. Following Preacher and colleagues (Preacher, Curran, \& Bauer, 2006), we examined the simple slope of the relationship between (a) positive affective tone and employee exhaustion and (b) negative affective tone and employee sick days at each possible value of consumercentric activity, which on its original scale ranged from 0 to $100 \%$. This approach to probing an interaction, which builds upon Aiken and West's (1991) work, is informative because it sheds light on how a relationship between two variables changes at many values of a moderator-not just at two selected values (e.g., +/- 1 SD from the mean). Panel A in Figure 3 provides a graph of the relationship between positive affective tone and emotional exhaustion at low $(0 \%)$ and high $(100 \%)$ levels of consumer-centric activity. Panel B in Figure 3 depicts the simple slope at every possible value of consumer-centric industry participation, along with $95 \%$ confidence bands around the simple slopes. As Figure 3 shows, the relationship between positive affective tone and employee exhaustion is significantly negative in firms with low participation in consumer-centric activity. The relationship in firms with high participation in consumer-centric activity is non-significant. Figure 4 provides these same kinds of graphs for the relationship between negative affective tone and sick days, at different levels of consumer-centric activity. As Panels A and B of Figure 4 show, negative affective tone had a positive relationship with employee sick days in firms with low participation in consumer-centric activity, while the 
relationship was positive in firms with high participation in consumer-centric activity. Note, however, that neither of these simple slopes was itself significantly different from zero.

Together with our results examining simple main effects of affective tone on workforce strain, these interaction findings paint a nuanced picture of how-across industries_-affective tone relates to workforce strain. We address the implications of these main and moderated effects of affective tone in detail in the discussion.

\section{DISCUSSION}

Why do some organizations feel different from others and why does this matter? Grounded in an open systems perspective, we developed and tested a conceptual model that connects an organization's domain of activity—-the kinds of industries in which it is active and where in the value chain it operates - to the nature and effects of organizational affective tone. The findings of our empirical study of 161 organizations provided general support for our conceptual model, but also raised questions for future research. First, consistent with our conceptual model, we found that the more an organization engages in consumer-centric activity, the more positive and less negative its organizational affective tone. The results of our variance decomposition analyses showed that this organizational affective tone is overarching-it transcends functional subunits within organizations in a way that fits with the core propositions of an open systems perspective. Second, and also consistent with our conceptual model, we found that organizational practices and structural elements served as mechanisms that connected customer centricity to organizational affective tone. Specifically, we found support for emotionfocused personnel practices and centralization as meso mechanisms that perpetuate organizational affective tone. We did not find that formalization played a role above and beyond these other mechanisms. Third, we found that organizational affective tone relates to workforce 
strain—employee exhaustion and employee absenteeism due to illness. In general, positive affective tone was associated with lower workforce strain, while negative affective tone was associated with higher workforce strain, but post-hoc analyses suggested that these effects might depend on how much an organization engages in consumer-centric activity. Given the costs associated with workforce strain these findings underscore the practical relevance of studying organizational affective tone.

\section{Theoretical Contributions}

Our theory and empirical findings introduce to the literature the idea that affective dynamics in organizations may have distal roots in the choices that founders and leaders make regarding how an organization creates value. By highlighting the role of an organization's domain-and, specifically, the degree to which an organization engages in consumer-centric activity - in precipitating organizational affective tone, we offer a new explanation for why the members of a collective converge in their affect. To explain the phenomenon of collective affect, existing theory and research have emphasized micro and interactional processes, such as emotional contagion and collective sensemaking (e.g., Elfenbein, 2014; Kelly \& Barsade, 2001). Missing in the literature is an explanation of how collective affect might result, instead, from more macro and institutional processes that lead employees to experience consistent positive or negative emotions (Menges \& Kilduff, 2015). Our conceptual model and findings reveal that organizational members' consistent ways of feeling at work stem, in a distal way, from the nature of an organization's domain of activities. We predict and find that employees' consistent affect - across an entire organization—-has roots in the degree to which the organization is active in consumer-centric activities that envelop or directly involve the end consumer. This overarching consistent organizational affective tone co-exists with and transcends any more 
locally shared feelings that may emerge within occupational groups or sub-units in organizations. Our research thus adds new insights to a burgeoning conversation about how and why affect converges in collectives larger than a small group (Hareli \& Rafaeli, 2008; Kelly \& Barsade, 2001; Menges \& Kilduff, 2015; Vuori \& Huy, 2016).

By explaining how personnel practices and organizational structure connect an organization's domain to organizational affective tone, we provide a meso perspective on collective affect that bridges macro organizational theory and micro organizational behavior. Our perspective responds to calls for theories that explain the mechanisms through which an organization's macro context might shape micro organizational behavior (Cappelli \& Sherer, 1991; House et al., 1995; Johns, 2006). Focused specifically on affect, scholars have lamented that "little empirical research has examined whether and how macro-level organizational structures and other factors generate similar or different emotions within and between key organizational groups" (Vuori \& Huy, 2016: 14). Our model directly specifies how macro-level organizational characteristics can precipitate consistent affect in organizations and, specifically, identifies a distal driver of affect. Our findings show that similar affect can arise across an entire organization, with roots in the choices that leaders make about how much to emphasize emotions in recruitment, selection, and promotion processes, as well as structural design choices concerning, especially, centralization. We thus find support for the idea that institutional mechanisms systematically embed organizational affective tone across an organization. Our paper explains both how organizational design choices are tied to the domains in which an organization is active, as well as how these choices contribute to the affective tone that pervades an organization. 
Our research also contributes new insights to the literature on workforce strain. Prior research on affect in organizations has suggested that collective affective characteristics of organizations may have an effect on workforce strain. This research was limited in scope, however, to specific field sites including the facilities of a long-term health care organization (Barsade \& O’Neill, 2014) and firefighting stations (O’Neill \& Rothbard, In Press). Drawing from the literature on workforce strain (i.e., Demerouti et al., 2001), we posited that organizational affective tone may act as a contextual demand or resource that affects organizational members in a relatively uniform way. Our large and diverse sample of organizations afforded the variance needed to test this idea in a set of organizations engaged in different kinds of activities and, in particular, which varied in their degree of customer centricity. Our research thus contributes to the expanding body of research examining connections between collective affect and workforce strain by showing that affective tone relates to workforce strain in a similar way across industries, but also, as the results of exploratory post-hoc analyses suggested, that this relationship may be contingent upon the nature of an organization's domain. This preliminary finding suggests possible new directions for understanding how an organization's affective context influences employees' well-being.

\section{Limitations, Theoretical Extensions, and Implications for Future Research}

Countering our predictions, we did not find that formalization mediated the relationship between customer centricity and organizational affective tone. Formalization refers to the extent to which an organization, through rules and regulations, explicitly prescribes certain employee behaviors and proscribes others (Hage \& Aiken, 1967; Pugh et al., 1968). We proposed that formalization would be relatively less helpful in the context of consumer centric activities, compared to activities buffered from the end user, and would, by way of depriving employees of 
autonomy, prevent a positive affective tone from emerging and instead diffuse a relatively negative affective tone throughout an organization. The bivariate correlations partially supported these propositions: There was a non-significant negative relationship between customer centricity and formalization; and, there were significant relationships between formalization and positive and negative affective tone in the expected directions. In our regression analyses, however, formalization did not explain additional variance in affective tone above and beyond personnel practices and centralization. Perhaps organizations with consumer centric activities are more formalized than we thought. Indeed, classic research on service occupations suggests that customer service interactions in some organization often follow tightly scripted patterns (Hochschild, 1979; Martin, Knopoff, \& Beckman, 1998). Future research should more closely examine the role of formalization, as a feature of organizational design, in the context of the collective affective dynamics that unfold in organizations across industries-both consumercentric and buffered from consumers.

Presenting other challenges to our conceptual model are the nuanced findings regarding the relationship between organizational affective tone and workforce strain. Replicating prior research in showing significant main effects of organizational affective tone on indicators of workforce strain (Barsade \& O’Neill, 2014; George, 1990; Mason \& Griffin, 2003), we found that negative affective tone was positively related to employee exhaustion. However, positive affective tone played a smaller role in predicting workforce strain, having a relatively weak negative relationship with employee sick days. In an attempt to understand why we might have observed weak relationships between positive affective tone and workforce strain, we examined in post hoc analyses the interactions between consumer centricity and affective tone. Our results showed conflicting interaction patterns. On the one hand, we found consumer centricity 
weakened the negative relationship between positive affective tone and employee exhaustion; in organizations highly involved in consumer-centric activity, positive affective tone provided less of a buffer to workforce strain. On the other hand, we found a crossover interaction between negative affective tone and employee sick days. The crossover pattern suggests that negative affective tone may increase absenteeism due to illness in organizations buffered from the consumer, but decrease absenteeism due to illness in consumer-centric industries. Because neither of these simple slopes was statistically significant, these results should be interpreted with caution.

In trying to understand these results, we conjectured that organizational affective tone might serve as less of a demand or resource, depending on the kind of work that an organization does. There are several other potential explanations, however. Perhaps the overarching focus and emphasis on emotions in organizations heavily engaged in consumer-centric activities leads employees in such organizations to become both more habituated to the experience of positive emotions and better equipped to deal with the experience of negative emotions than employees in the more rationalized context of organizations buffered from the consumer (Frijda, 1988). Alternatively, perhaps a transformation process in which consumers are central to value creation provides employees with a connection to the beneficiaries of their work that is closer and clearer than a transformation process buffered from end users. Understanding how others benefit from their work may provide an alternative buffer to workplace stressors (Grant, 2007, 2012) and replenish the resources of employees who work in organizations engaged in consumer-centric activity (Glomb, Kammeyer-Mueller, \& Rotundo, 2004). A domain with consumer-centric activity may thus be a substitute to the effects of organizational affective tone on workforce strain. In the absence of this substitute — such as in an organization engaged primarily in 
manufacturing - the effects of affective tone on workforce strain may be more pronounced.

Without a clear connection to beneficiaries, organizations' positive affective tone may serve an especially important role in buffering from workplace stressors, while negative tone may magnify these stressors. Future research is needed to probe the mechanisms through which these interactive effects might shape workforce strain.

Our introduction of an organization's domain of activity as a distal input into affective dynamics in organizations has a number of implications for theory and future research, as well as for practice. First, our findings suggest that senior leaders who choose to engage in vertical integration-either moving forward in the value chain into consumer-centric activity or backward into activities buffered from the consumer-may provoke a unique set of affective challenges. Our findings provide clues that senior leaders can play an important role, through their decisions about organizational design and personnel practices, in shaping the consistent affect that characterizes an organization. Additionally, it is possible that leaders' behavior during this type of change, along with training and development programs, can encourage a new consideration of the role of affect in the work of the firm (e.g., Kotter, 1995). However, our conceptual model and prior theory (e.g., Schein, 2010; Schneider, 1987) suggest that change in affective tone-even with supportive leader behavior, changes to organizational design, and new personnel practices - is likely to be slow. If organizational affective tone arises, in part, as a function of the people that an organization attracts, selects, and retains (George, 1990), dramatic shifts in affective tone may only occur as the composition of the workforce itself shifts. It could thus take a very long time for an organization that vertically integrates to internally cultivate the affective tone needed to move forward or backward in the value chain. 
These challenges may be particularly acute when firms undergo vertical integration through mergers or acquisitions. Researchers and practitioners commonly point to a clash of company cultures as a primary source of tension and failure in mergers and acquisitions (Graebner, Heimeriks, Huy, \& Vaara, In Press; Van den Steen, 2010). For a merger between a company that is heavily involved in consumer-centric activity and one that is significantly buffered from the consumer, our research identifies a new, more specific dimension of organizational context on which these companies are likely to clash—affective tone. Because of the different implicit assumptions about the role of emotion in consumer-centric activities, versus buffered activities in manufacturing, the current and aspirational affective tone in these organizations may be quite different. Theory and research are needed, in particular, on the affective dimension of cultural integration in mergers and acquisitions, as well as on the temporal processes by which organizations dynamically change in affective tone when expanding their operations to new activities.

We have argued that the degree to which an organization's domain comprises consumercentric activity is an important macro characteristic that shapes affect in organizations. Our arguments flowed from a core axiom of open systems theory, which is that leaders make choices about organizational design and personnel, ultimately, in the service of the core transformation process (Katz \& Kahn, 1978). An additional tenet of an open systems perspective, however, is that the boundaries of organizations are permeable and, as such, elements of an organization's environment may also play a role in shaping and altering organizational affective tone. An important avenue for future research is the examination of other macroscopic factors that may contribute to employees' affect. One factor that may play an important role, but that we did not consider in this study, is the strength of the economy in which an organization is embedded-a 
factor that was held mostly constant in our sample of firms from one particular national economy during one period of time. It is possible that an organization's affective tone, which we argued is shaped in part by the selection and retention of employees, fluctuates with the strength of the economy. During economic downturns, it is possible that organizational affective tone becomes less positive and more negative. An alternative argument, however, is that an organization's affective tone provides a buffer against the stress induced by short-term fluctuations in the economy. In an organization with a strong positive affective tone, short-term downturns may have less of an effect on employee attitudes and behavior. Theory and research are needed to explore how other macro factors influence affect in organizations.

Our central argument that organizational affective tone is connected to an organization's domain of activity overlooks the possibility that senior leaders adopt strategic positions that deviate from the average tendency that we observed. Said differently, we focused in this paper on the general tendency of organizations engaged in consumer-focused activity, rather than on strategic choices that may create variance within industries. Anecdotal examples, our findings regarding interactive effects of affective tone on workforce strain, and upper echelons theory (e.g., Hambrick, 2007) all suggest that there is value in considering the antecedents and consequences of deviations from the general tendency that we observe. Extending our earlier example, in which we compared Southwest Airlines to Boeing, there may be value in considering whether and why Southwest Airlines has an affective tone that is relatively more positive and less negative than, say, American Airlines. As theorists have suggested (i.e., Schneider, 1987; Schein, 2010), although organizational norms are shaped by the decisions that organizational leaders make regarding the industries in which to compete-and, thus, the structures and practices needed within those industries—-norms are also shaped by decisions 
regarding how to compete within those industries. Some founders and leaders may decide to compete on cost and price, while others may decide to compete on quality and service. Research is needed to explore how the strategic choices that leaders make within industry might further shape organizational affective tone.

Our theory and findings suggest implications for the large and long-running literature on emotional labor in organizations (Grandey \& Gabriel, 2015). Scholarship from this tradition has typically examined consumer-centric activity as an occupational characteristic intrinsic to certain jobs. The emphasis in emotional labor research has usually been on how employees in service roles regulate their emotions in order to deliver effective customer service interactions and on how different emotion regulation tendencies relate to workforce strain (e.g., Brotheridge \& Grandey, 2002; Glomb et al., 2004; Hochschild, 1983). In our research, in contrast, we have examined consumer-centric activity as an organizational characteristic, building upon the idea from open systems theory that a dominant logic stemming from an organization's overarching purpose permeates sub-system boundaries. Our variance decomposition findings suggest that organizations, indeed, possess an overarching affective tone-one that transcends occupational and subunit variance in affect (Diefendorff et al., 2011). Further, in our analyses, we controlled for how openly and authentically employees believed they could express their emotions, in an effort to focus specifically on affective experiences, rather than on the effects of expressive emotion regulation norms that are peripheral to the focus of this paper. Although we only included this variable as a control, our empirical results reveal that there is a promising opportunity for future research that examines the intersection of consumer centricity, affective tone, and norms regarding the expression of emotion. Intriguingly, and somewhat at odds with classic theory on emotional labor (i.e., Hochschild, 1983), we observed a positive relationship 
between consumer centric activity and norms supporting the open expression of emotion $(\mathrm{r}=$ $0.17, p<0.05)$. One possible explanation for this is that although emotional expression is regulated in organizations engaged in customer service and retail, the presumption that emotions intrude on task performance (Ashforth \& Humphrey, 1996) creates even more onerous constraints on emotional expression. This is, of course, just speculation. However, our findings indicate that a particularly fruitful direction for future scholarship is to unite the literature on affective tone with the literature on emotion regulation.

Finally, from a methodological viewpoint, we acknowledge that the breadth of our sample required some tradeoffs concerning research design; our findings must be interpreted in light of those tradeoffs. On the positive side, we were able to acquire data from multiple sources-including employees, a representative from human resources, and members of the top management — across a relatively large number of organizations engaged in a diverse range of activities. The unique nature of this sample enabled us to test meso theory about how an organization's domain connects to its affective tone. On the negative side, our sample comprised medium-sized German firms. Research is needed to confirm the generalizability of our findings to firms based in other nations and also to larger organizations, such as multinational conglomerates. Our split-sample design also restricted our analysis to the firm level of analysis, preventing us from testing potential cross-level interactions that may be especially relevant for understanding the relationship between organizational affective tone and workforce strain. Prior research in both the literature on workforce strain (e.g., Ganster \& Rosen, 2013) and on organizational affect (e.g., Barsade \& O’Neill, 2014) suggest that individual trait affectivity may play an important role, such that some people are more affected than others by the overarching 
affective context in which they work. Without data on individual trait affectivity, we were not able to test for such effects.

The cross-sectional nature of our research design renders conclusions about causality necessarily tentative. It is unlikely, however, that reverse causality could account for the associations that we observe between consumer-centric activity and affective tone: whether an organization makes a strategic choice to compete in consumer centric activities is unlikely to stem from consistent feelings of positivity or negativity among employees. Similarly, it is unlikely that decisions about organizational structure or personnel practices are caused by affective tone. Our findings regarding the connection between affective tone and workforce strain are more vulnerable to concerns about reverse causality. We tried to ameliorate such concerns empirically through control variables (e.g., we controlled for sick days in the year prior and for top managers' common beliefs about prior firm performance) and theoretically through the replicative nature of our hypothesizing; and, indeed, our results partially replicate the findings of prior research. Nevertheless, to gain more certainty about the causal ordering of our conceptual model, a longitudinal or quasi-experimental research design is needed.

\section{Conclusion}

Organizations feel different, in part, because organizational affective tone develops to help organizations transform inputs into more valuable outputs. Organizations are open systems of interrelated parts - parts that are connected by a common logic stemming from the kinds of activities in which an organization engages. Our meso perspective highlights the value of considering the macro and overarching context of an organization to understand the origins and effects of affect. 


\section{REFERENCES}

Arvey, R. D., Renz, G. L., \& Watson, W. W. 1998. Emotionality and job performance: Implications for personnel selection. In G. R. Ferris (Ed.), Research in personnel and human resource management, Vol. 16: 103-147. Greenwich, CT: JAI Press.

Ashforth, B. E., \& Humphrey, R. H. 1995. Emotion in the workplace: A reappraisal. Human Relations, 48: 97-125.

Barsade, S. G. 2002. The ripple effect: Emotional contagion and its influence on group behavior. Administrative Science Quarterly, 47: 644-675.

Barsade, S. G., \& Gibson, D. E. 2007. Why does affect matter in organizations? Academy of Management Perspectives, 21: 36-59.

Barsade, S. G., \& Knight, A. P. 2015. Group affect. Annual Review of Organizational Psychology and Organizational Behavior, 2: 21-46.

Barsade, S. G., \& O’Neill, O. A. 2014. What's Love Got to Do with It? A Longitudinal Study of the Culture of Companionate Love and Employee and Client Outcomes in a Long-term Care Setting. Administrative Science Quarterly, 54: 551-598.

Bartel, C. A., \& Saavedra, R. 2000. The collective constrution of work group moods. Administrative Science Quarterly, 45: 197-231.

Becker, T. E. 2005. Potential problems in the statistical control of variables in organizational research: A qualitative analysis with recommendations. Organizational Research Methods, 8: 274-289.

Bliese, P. D. 1998. Group size, ICC values, and group-level correlations: A simulation. Organizational Research Methods, 1: 355-373.

Bliese, P. D. 2000. Within-group agreement, non-independence, and reliability: Implications for data aggregation and analysis. In K. J. Klein \& S. W. J. Kozlowski (Eds.), Multilevel theory, research, and methods in organizations: Foundations, extensions, and new directions: 349-381. San Francisco, CA: Jossey-Bass.

Bono, J. E., Glomb, T. M., Shen, W., Kim, E., \& Koch, A. J. 2013. Building positive resources: Effects of positive events and positive reflection on work stress and health. Academy of Management Journal, 56: 1601-1627.

Brotheridge, C. M., \& Grandey, A. A. 2002. Emotional labor and burnout: Comparing two perspectives of "people work." Journal of Vocational Behavior, 60: 17-39.

Cappelli, P., \& Sherer, P. D. 1991. Them missing role of context in OB: The need for a mesolevel approach. Research in Organizational Behavior, 13: 55-110.

Carlson, K. E., \& Wu, J. 2012. The illusion of statistical control: Control variable practice in management research. Organizational Research Methods, 15: 413-435.

Chan, D. 1998. Functional relations among constructs in the same content domain at different levels of analysis: A typology of composition models. Journal of Applied Psychology, 83: 234-246.

Chandler, A. D. 1962. Strategy and structure: Chapters in the history of the American industrial enterprise. Cambridge: MIT Press.

Chatman, J. A. 1991. Matching people and organizations: Selection and socialization in public accounting firms. Administrative Science Quarterly, 36: 459-484.

Chen, G., Mathieu, J. E., \& Bliese, P. D. 2004. A framework for conducting multi-level construct validation. Research in Multi-Level Issues, 3: 273-303.

Child, J. 1973. Predicting and understanding organizational structure. Administrative Science Quarterly, 18: 168-185. 
Cialdini, R. B., Reno, R. R., \& Kallgren, C. A. 1990. A focus theory of normative conduct: Recycling the concept of norms to reduce littering in public places. Journal of Personality and Social Psychology, 58: 1015-1026.

Côté, S. 2005. A social interaction model of the effects of emotion regulation on work strain. Academy of Management Review, 30: 509-530.

Daft, R. 2006. Organization theory and design (9th ed.). Mason, OH: Thomson.

Damasio, A. 1994. Descartes' error: Emotion, reason, and the human brain. New York: Grosset.

Davis, K., Collins, S. R., Doty, M. M., Ho, A., \& Holmgren, A. L. 2005. Health and productivity among U.S. workers. New York, NY: Commonwealth Fund.

Demerouti, E., Bakker, A. B., Nachreiner, F., \& Schaufeli, W. B. 2001. The job demandsresources model of burnout. Journal of Applied Psychology, 86: 499-512.

Diefendorff, J. M., Croyle, M. H., \& Gosserand, R. H. 2005. The dimensionality and antecedents of emotional labor strategies. Journal of Vocational Behavior, 66: 339-357.

Diefendorff, J. M., Erickson, R. J., Grandey, A. A., \& Dahling, J. J. 2011. Emotional display rules as work unit norms: A multilevel analysis of emotional labor among nurses. Journal of Occupational Health Psychology, 16: 170-186.

Dierdorff, E. C., \& Morgeson, F. P. 2013. Getting what the occupation gives: Exploring multilevel links between work design and occupational values. Personnel Psychology, 66: 687-721.

Elfenbein, H. A. 2014. The many faces of emotional contagion: An affective process theory of affective link. Organizational Psychology Review, 4: 326-362.

Fredrickson, B. L. 1998. What good are positive emotions? Review of General Psychology, 2: 300-319.

Frijda, N. H. 1988. The laws of emotion. American Psychologist, 43: 349-358.

Ganster, D. C., \& Rosen, C. C. 2013. Work stress and employee health: A multidisciplinary review. Journal of Management, 39: 1085-1122.

George, J. M. 1990. Personality, affect, and behavior in groups. Journal of Applied Psychology, 75: 107-116.

George, J. M. 1996. Group affective tone. In M. A. West (Ed.), Handbook of work group psychology: 77-93. Chichester, UK: Wiley.

Glomb, T. M., Kammeyer-Mueller, J. D., \& Rotundo, M. 2004. Emotional labor demands and compensating wage differentials. Journal of Applied Psychology, 89: 700-714.

Graebner, M., Heimeriks, K., Huy, Q., \& Vaara, E. In Press. The process of postmerger integration: A review and agenda for future research. Academy of Management Annals.

Grandey, A. A. 2000. Emotion regulation in the workplace: A new way to conceptualize emotional labor. Journal of Occupational Health Psychology, 5: 95-110.

Grandey, A. A., Diefendorff, J. M., \& Rupp, D. E. 2013. Bringing emotional labor into focus: A review and integration of three research lenses. In A. A. Grandey, J. M. Diefendorff, \& D. E. Rupp (Eds.), Emotional labor in the 21st century: 3-28. New York, NY: Routledge.

Grandey, A. A., \& Gabriel, A. S. 2015. Emotional labor at a crossroads: Where do we go from here? Annual Review of Organizational Psychology and Organizational Behavior, 2: 323-349.

Grant, A. M. 2007. Relational job design and the motivation to make a prosocial difference. Academy of Management Review, 32: 393-417.

Grant, A. M. 2012. Leading with meaning: Benificiary contact, prosocial impact, and the 
performance effects of transformational leadership. Academy of Management Journal, 55: $458-476$.

Hage, J., \& Aiken, M. 1967. Relationship of Centralization to Other Structural Properties. Administrative Science Quarterly, 12: 72-92.

Hambrick, D. C. 2007. Upper echelons theory: An update. Academy of Management Review, 32: 334-343.

Hareli, S., \& Rafaeli, A. 2008. Emotion cycles: On the social influence of emotion in organizations. Research in Organizational Behavior, 28: 35-59.

Hatfield, E., Cacioppo, R., \& Rapson, R. 1994. Emotional Contagion. New York: Cambridge University Press.

Hill, T. P. 1977. On goods and services. Review of Income \& Wealth, 23: 315-338.

Hochschild, A. R. 1979. Emotion work, feeling rules, and social structure. American Journal of Sociology, 85: 551-575.

Hochschild, A. R. 1983. The managed heart: The commercialization of human feeling. Berkeley, CA: The University of California Press.

House, R. J., Rousseau, D. M., \& Thomas-Hunt, M. 1995. The meso paradigm: A framework for the integration of micro and macro organizational behavior. Research in Organizational Behavior, 17: 71-114.

Jackson, S. E., \& Schuler, R. S. 1985. A meta-analysis and conceptual critique of research on role ambiguity and role conflict in work settings. Organizational Behavior and Human Decision Processes, 36: 16-78.

Jackson, S. E., Schuler, R. S., \& Rivero, J. C. 1989. Organiztaional characteristics as predictors of personnel practices. Personnel Psychology, 42: 727-786.

Jansen, J. J. P., Van Den Bosch, F. A. J., \& Volberda, H. W. 2006. Exploratory innovation, exploitative innovation, and performance: Effects of organizational antecedents and environmental moderators. Management Science, 52: 1661-1674.

Johns, G. 2006. The essential impact of context on organizational behavior. Academy of Management Review, 31: 386-408.

Katz, D., \& Kahn, R. L. 1978. The social psychology of organizations. New York: Wiley.

Kelley, S. W., \& Hoffman, K. D. 1997. An investigation of positive affect, prosocial behaviors and service quality. Journal of Retailing, 73: 407-427.

Kelly, J. R., \& Barsade, S. G. 2001. Mood and emotions in small groups and work teams. Organizational Behavior and Human Decision Processes, 86: 99-130.

Kimberly, J. R. 1976. Organiztaional size and the structuralist perspective: A review, critique, and proposal. Administrative Science Quarterly, 21: 571-597.Klein, K. J., \& Kozlowski, S. W. J. 2000. From micro to meso: Critical steps in conceptualizing and conducting multilevel research. Organizational Research Methods, 3: 211-236.

Kline, R. B. 2011. Principles and practice of structural equation modeling, $3^{\text {rd }}$ Edition. New York: Guilford Press.

Knight, A. P., \& Eisenkraft, N. 2015. Positive is usually good, negative is not always bad: The effects of group affect on social integration and task performance. Journal of Applied Psychology, 100: 1214-1227.

Knowles, P. A., Grove, S. J., \& Pickett, G. M. 1993. Mood and the service customer: Review and propositions. Journal of Services Marketing, 7: 41-52.

Kotter, J. P. 1995. Leading change: Why transformation efforts fail. Harvard Business Review, March-April: 59-67. 
Kozlowski, S. W. J., \& Klein, K. J. 2000. A multilevel approach to theory and research in organizations: Contextual, temporal, and emergent processes. In K. J. Klein \& S. W. J. Kozlowski (Eds.), Multilevel theory, research, and methods in organizations: Foundations, extensions, and new directions: 3-90. San Francisco, CA: Jossey-Bass.

Levine, S., \& White, P. E. 1961. Exchange as a conceptual framework for the study of interorganizational relationships. Administrative Science Quarterly, 5: 583-601.

Lovelock, C. H. 1983. Classifying services to gain strategic marketing insights. Journal of Marketing, 47: 9-20.

Lovelock, C. H. 2001. Services marketing: People, technology, and strategy. Upper Saddle River, NJ: Prentice-Hall.

Lyubomirsky, S., King, L., \& Diener, E. 2005. The benefits of frequent positive affect: Does happiness lead to success? Psychological Bulletin, 131: 803-855.

Mackinnon, D. P., \& Fairchild, A. J. 2009. Current directions in mediation analysis. Current Directions in Psychological Science, 18: 16-20.

Mann, S. 1999. Emotion at work: To what extent are we expressing, suppressing, or faking it? European Journal of Work and Organizational Psychology, 8: 347-369.

Martin, J., Knopoff, K., \& Beckman, C. 1998. An alternative to bureaucratic impersonality and emotional labor: Bounded emotionality at The Body Shop. Administrative Science Quarterly, 43: 429-469.

Maslach, C., \& Jackson, S. E. 1981. The measurement of experienced burnout. Journal of Occupational Behaviour, 2: 99-113.

Mason, C. M., \& Griffin, M. A. 2003. Group absenteeism and positive affective tone: a longitudinal study. Journal of Organizational Behavior, 24: 667-687.

Menges, J. I., \& Kilduff, M. 2015. Group emotions: Cutting the Gordian knots concerning terms, levels-of-analysis, and processes. Academy of Management Annals, 9: 845-928.

Mills, P. K., \& Moberg, D. J. 1982. Perspectives on the technology of service operations. Academy of Management Review, 7: 467-478.

Mumby, D. K., \& Putnam, L. L. 1992. The politics of emotion: A feminist reading of bounded rationality. Academy of Management Review, 17: 465-486.

Nesterkin, D. A., \& Ganster, D. C. 2015. The effects of nonresponse rates on group-level correlations. Journal of Management, 41: 789-807.

Ng, T. W. H., \& Feldman, D. C. 2008. The relationship of age to ten dimensions of job performance. Journal of Applied Psychology, 93: 392-423.

O’Neill, O. A., \& Rothbard, N. In Press. Is love all you need? The effects of emotional culture, suppression, and work-family conflict on firefighter risk taking and health. Academy of Management Journal.

Oldham, G. R., \& Hackman, J. R. 1981. Relationships between organizational structure and employee reactions: Comparing alternative frameworks. Administrative Science Quarterly, 26: 66-83.

Oliver, R. L., Rust, R. T., \& Varki, S. 1997. Customer delight: Foundations, findings, and managerial insight. Journal of Retailing, 73: 311-336.

Parke, M. R., \& Seo, M. In Press. The role of affect climate in organizations. Academy of Management Review.

Podsakoff, P. M., MacKenzie, S. B., Lee, J.-Y., \& Podsakoff, N. P. 2003. Common method biases in behavioral research: A critical review of the literature and recommended remedies. Journal of Applied Psychology, 88: 879-903. 
Preacher, K. J., Curran, P. J., \& Bauer, D. J. 2006. Computational tools for probing interactions in multiple linear regression, multilevel modeling, and latent curve analysis. Journal of Educational and Behavioral Statistics, 31: 437-448.

Pugh, D. S., Hickson, D. J., Hinings, C. R., \& Turner, C. 1968. Dimensions of organization structure. Administrative Science Quarterly, 13: 65-105.

Pugh, D. S., Hickson, D. J., Hinings, C. R., \& Turner, C. 1969. The context of organizational structures. Administrative Science Quarterly, 14: 91-114.

Pugh, S. D. 2001. Service with a smile: Emotional contagion in the service encounter. Academy of Management Journal, 44: 1018-1027.

Rafaeli, A., \& Sutton, R. I. 1987. Expression of emotion as part of the work role. Academy of Management Review, 12: 23-37.

Rodell, J. B., \& Judge, T. A. 2009. Can "good" stressors spark "bad" behaviors? The mediating role of emotions in links of challenge and hindrance stressors with citizenship and counterproductive behaviors. Journal of Applied Psychology, 94: 1438-1451.

Rousseau, D. M. 1985. Issues of level in organizational research: Multi-level and cross-level perspectives. Research in Organizational Behavior, 7: 1-37.

Rousseau, D. M., \& House, R. J. 1994. Meso organizational behavior: Avoiding three fundamental biases. In C. L. Cooper \& D. M. Rousseau (Eds.), Trends in organizational behavior, Vol. 1: 13-30. John Wiley \& Sons Ltd.

Schein, E. H. 2010. Organizational culture and leadership (4th ed.). San Francisco, CA: JosseyBass.

Schminke, M., Ambrose, M. L., \& Cropanzano, R. S. 2000. The effect of organizational structure on perceptions of procedural fairness. Journal of Applied Psychology, 85: 294304.

Schminke, M., Cropanzano, R., \& Rupp, D. E. 2002. Organization structure and fairness perceptions: The moderating effects of organizational level. Organizational Behavior and Human Decision Processes, 89: 881-905.

Schaubroeck, J., Ganster, D. C., \& Jones, J. R. 1998. Organization and occupation influences in the attraction-selection-attrition process. Journal of Applied Psychology, 83: 869-891.

Schneider, B. 1987. The people make the place. Personnel Psychology, 40: 437-453.

Schneider, B., \& Bowen, D. E. 1995. Winning the service game. Boston, MA: Harvard Business School Press.

Schneider, B., \& Bowen, D. E. 1999. Understanding customer delight and outrage. Sloan Management Review, 41: 35-45.

Schneider, B., Ehrhart, M. G., \& Macey, W. H. 2013. Organizational climate and culture. Annual Review of Psychology, 64: 361-388.

Schneider, B., Goldstein, H. W., \& Smith, D. B. 1995. The ASA framework: An update. Personnel Psychology, 48: 747-773.

Schneider, B., Hanges, P. J., Smith, D. B., \& Salvaggio, A. N. 2003. Which comes first: Employee attitudes or organizational financial and market performance. Journal of Applied Psychology, 88: 836-851.

Schneider, B., \& White, S. S. 2004. Service quality: Research perspectives. Thousand Oaks, CA: Sage Publications.

Seo, M., \& Barrett, L. F. 2007. Being emotional during decision making: Good or bad? An empirical investigation. Academy of Management Journal, 50: 923-940.

Sine, W. D., Mitsuhashi, H., \& Kirsch, D. A. 2006. Revisiting Burns and Stalker: Formal 
structure and new venture performance in emerging economic sectors. Academy of Management Journal, 49: 121-132.

Song, Z., Foo, M. D., \& Uy, M. A. 2008. Mood spillover and crossover among dual-earner couples: A cell phone event sampling study. Journal of Applied Psychology, 93: 443-452.

Sutton, R. I. 1991. Maintaining norms about expressed emotions: The case of bill collectors. Administrative Science Quarterly, 36: 245-268.

Sy, T., Côté, S., \& Saavedra, R. 2005. The contagious leader: Impact of the leader's mood on the mood of group members, group affective tone, and group processes. Journal of Applied Psychology, 90: 295-305.

Thompson, J. D. 1967. Organizations in action: Social science bases of administrative theory. New York: McGraw-Hill.

Totterdell, P., Wall, T., Holman, D., Diamond, H., \& Epitropaki, O. 2004. Affect networks: A structural analysis of the relationship between work ties and job-related affect. Journal of Applied Psychology, 89: 854-867.

U. S. Census Bureau. 2016. Industry statistics portal. Retrieved November 1, 2016, from https://www.census.gov/econ/isp/.

Van den Steen, E. 2010. Culture clash: The costs and benefits of homogeneity. Management Science, 56: 1718-1738.

Van Katwyk, P. T., Fox, S., Spector, P. E., \& Kelloway, E. K. 2000. Using the job-related affective well-being scale (JAWS) to investigate affective responses to work stressors. Journal of Occupational Health Psychology, 5: 219-230.

Van Kleef, G. A., Homan, A. C., Beersma, B., van Knippenberg, D., van Knippenberg, B., \& Damen, F. 2009. Searing sentiment or cold calculation? The effects of leader emotional displays on team performance depend on follower epistemic motivation. Academy of Management Journal, 52: 562-580.

Verma, H. V. 2003. Customer outrage and delight. Journal of Services Research, 3: 119-133.

Vuori, T. O., \& Huy, Q. N. 2016. Distributed attention and shared emotions in the innovation process. Administrative Science Quarterly, 61: 9-51.

Weber, M. 1978. Economy and society: An outline of interpretive sociology. (G. Roth \& C. Wittich, Eds.). Berkeley, CA: University of California Press.

Zohar, D., \& Luria, G. 2005. A multilevel model of safety climate: Cross-level relationships between organization and group-level climates. Journal of Applied Psychology, 90: 616628. 
TABLE 1

Descriptive Statistics and Correlations among Study Variables

\begin{tabular}{|c|c|c|c|c|c|c|c|c|c|c|c|c|c|c|c|c|}
\hline & $M$ & $S D$ & 1 & 2 & 3 & 4 & 5 & 6 & 7 & 8 & 9 & 10 & 11 & 12 & 13 & 14 \\
\hline 1. Firm size $(\log )$ & 5.08 & 1.19 & & & & & & & & & & & & & & \\
\hline 2. Firm age & 44.57 & 44.52 & .32 & & & & & & & & & & & & & \\
\hline 3. Firm unionization & 6.68 & 16.44 & .22 & .10 & & & & & & & & & & & & \\
\hline 4. Expression norms & 4.67 & .50 & -.28 & -.12 & -.11 & $(.90)$ & & & & & & & & & & \\
\hline 5. Employee age & 37.97 & 3.95 & .20 & .29 & .17 & -.17 & & & & & & & & & & \\
\hline 6. Prior year sick days & 6.51 & 3.45 & .32 & .11 & .34 & -.29 & .30 & & & & & & & & & \\
\hline 7. Prior year firm performance & 5.80 & 1.08 & -.15 & -.09 & .05 & .06 & -.06 & .10 & $(.91)$ & & & & & & & \\
\hline 8. Consumer-centric activity & 56.93 & 46.08 & -.04 & -.35 & -.17 & .17 & -.10 & -.21 & .00 & & & & & & & \\
\hline $\begin{array}{l}\text { 9. Emotion-focused personnel } \\
\text { practices }\end{array}$ & 4.85 & .90 & -.12 & -.04 & -.06 & .11 & -.08 & -.07 & .20 & .17 & $(.78)$ & & & & & \\
\hline 10. Formalization & 4.14 & .68 & .28 & .12 & .14 & -.16 & .15 & .22 & .09 & -.12 & -.02 & $(.82)$ & & & & \\
\hline 11. Centralization & 3.24 & .75 & .41 & .19 & .26 & -.63 & .32 & .36 & -.09 & -.27 & -.08 & .40 & $(.98)$ & & & \\
\hline 12. Positive affective tone & 3.37 & .36 & -.33 & -.25 & -.21 & .61 & -.30 & -.41 & .16 & .36 & .24 & -.19 & -.71 & $(.96)$ & & \\
\hline 13. Negative affective tone & 2.19 & .34 & .40 & .23 & .19 & -.58 & .33 & .44 & -.19 & -.28 & -.18 & .19 & .66 & -.80 & $(.94)$ & \\
\hline 14. Employee exhaustion & 2.50 & .41 & .19 & .09 & .12 & -.35 & .01 & .22 & -.14 & -.13 & -.14 & .06 & .42 & -.45 & .53 & $(.88)$ \\
\hline 15. Employee sick days & 4.23 & 2.65 & .29 & .07 & .24 & -.28 & .23 & .67 & .13 & -.16 & -.02 & .15 & .33 & -.33 & .32 & .20 \\
\hline
\end{tabular}
Note. $N=161$ firms for all variables except prior year sick days $(N=157)$, sick days $(N=158)$, and prior year firm performance $(N=$ 130). Interitem reliability is provided in parentheses along the diagonal for multi-item scales. 
TABLE 2

Results of OLS Analyses Examining Antecedents of Organizational Affective Tone

\begin{tabular}{|c|c|c|c|c|c|c|}
\hline & \multicolumn{3}{|c|}{ Positive Affective Tone } & \multicolumn{3}{|c|}{ Negative Affective Tone } \\
\hline & Model 1 & Model 2 & Model 3 & Model 4 & Model 5 & Model 6 \\
\hline & $\overline{\beta S E}$ & $\overline{\beta S E}$ & $\overline{\beta S E}$ & $\overline{\beta S E}$ & $\overline{\beta S E}$ & $\overline{\beta S E}$ \\
\hline Firm size & $-.11(.07)$ & $-.15(.07)^{*}$ & $-.03(.06)$ & $.22(.07)^{*}$ & $.24(.07)^{*}$ & $.15(.07)^{*}$ \\
\hline Firm age & $-.13(.06)^{*}$ & $-.05(.07)$ & $-.06(.06)$ & $.09(.06)$ & $.03(.07)$ & $.04(.06)$ \\
\hline Firm unionization & $-.11(.06)^{+}$ & $-.08(.06)$ & $-.02(.05)$ & $.08(.06)$ & $.05(.06)$ & $.00(.06)$ \\
\hline Expression norms & $.55(.06)^{*}$ & $.51(.06)^{*}$ & $.24(.07)^{*}$ & $-.50(.06)^{*}$ & $-.48(.06)^{*}$ & $-.25(.07)^{*}$ \\
\hline Consumer-centric activity & & $.24(.06)^{*}$ & $.14(.06)^{*}$ & & $-.17(.07)^{*}$ & $-.10(.06)$ \\
\hline Emotion-focused & & & $.14(.05)^{*}$ & & & $-.08(.06)$ \\
\hline personnel practices & & & & & & \\
\hline Formalization & & & $.08(.06)$ & & & $-.08(.06)$ \\
\hline Centralization & & & $-.51(.08)^{*}$ & & & $.44(.08)^{*}$ \\
\hline$D F$ & 4,156 & 5,155 & 8,152 & 4,156 & 5,155 & 8,152 \\
\hline$R^{2}$ & 0.43 & 0.47 & 0.61 & 0.42 & 0.44 & 0.53 \\
\hline$F$ & 28.97 & 27.84 & 29.37 & 27.77 & 24.38 & 21.54 \\
\hline
\end{tabular}

Note. $N=161$ firms. Entries are standardized coefficients and (standard errors).

${ }^{+} p<.10 ;{ }^{*} p<.05$; two-tailed tests 
TABLE 3

Results of OLS Analyses Examining Mechanisms that Embed Organizational Affective Tone

\begin{tabular}{|c|c|c|c|c|c|c|}
\hline & \multicolumn{2}{|c|}{$\begin{array}{l}\text { Emotion-Focused } \\
\text { Personnel Practices }\end{array}$} & \multicolumn{2}{|c|}{ Formalization } & \multicolumn{2}{|c|}{ Centralization } \\
\hline & Model 1 & Model 2 & Model 3 & Model 4 & Model 5 & Model 6 \\
\hline & $\beta \quad S E$ & $\beta S E$ & $\beta \quad S E$ & $\beta \quad S E$ & $\beta S E$ & $\beta S E$ \\
\hline Firm size & $\begin{array}{ll}.09 & (.09)\end{array}$ & $\begin{array}{ll}-.12 \quad(.09) \\
\end{array}$ & $(.08)^{*}$ & $(.09)^{*}$ & $(.06)^{*}$ & $(.06)^{*}$ \\
\hline Firm age & $.00 \quad(.08)$ & $.07 \quad(.09)$ & $(.08)$ & $(.09)$ & $(.06)$ & $(.06)$ \\
\hline Firm unionization & $-.03 \quad(.08)$ & $-.01 \quad(.08)$ & $(.08)$ & $(.08)$ & $(.06)^{*}$ & $(.06)^{*}$ \\
\hline Expression norms & $.08 \quad(.08)$ & $(.08)$ & $(.08)$ & $(.08)$ & $(.06)^{*}$ & $(.06)^{*}$ \\
\hline $\begin{array}{l}\text { Consumer-centric } \\
\text { activity }\end{array}$ & & $.18(.09)^{*}$ & & $(.08)$ & & $(.06)^{*}$ \\
\hline$D F$ & 4,156 & 5,155 & 4,156 & 5,155 & 4,156 & 5,155 \\
\hline$R^{2}$ & 0.02 & 0.05 & 0.09 & 0.1 & 0.48 & 0.5 \\
\hline$F$ & 0.89 & 1.62 & 3.85 & 3.28 & 35.72 & 30.81 \\
\hline
\end{tabular}

Note. $N=161$ firms. Entries are standardized coefficients and (standard errors).

${ }^{+} p<.10 ;{ }^{*} p<.05 ;$ two-tailed tests 
TABLE 4

Results of OLS Analyses Examining the Effects of Organizational Affective Tone

\begin{tabular}{|c|c|c|c|c|c|c|c|c|}
\hline & \multicolumn{4}{|c|}{ Employee Exhaustion } & \multicolumn{4}{|c|}{ Employee Sick Days } \\
\hline & \multicolumn{2}{|c|}{$\underline{\text { Model } 1}$} & \multicolumn{2}{|c|}{$\underline{\text { Model } 2}$} & \multicolumn{2}{|c|}{ Model 3} & \multicolumn{2}{|c|}{$\underline{\text { Model } 4}$} \\
\hline & $\beta$ & $\overline{S E}$ & $\bar{\beta}$ & $\overline{S E}$ & $\beta$ & $\overline{S E}$ & $\bar{\beta}$ & $\overline{S E}$ \\
\hline Firm size & .00 & $(.09)$ & -.06 & $(.09)$ & .09 & $(.07)$ & .10 & $(.08)$ \\
\hline Firm age & .05 & $(.09)$ & .03 & $(.08)$ & -.07 & $(.07)$ & -.08 & $(.07)$ \\
\hline Firm unionization & .04 & $(.10)$ & .04 & $(.09)$ & .04 & $(.08)$ & .03 & $(.08)$ \\
\hline Expression norms & -.30 & $(.11)^{*}$ & -.19 & $(.11)^{+}$ & -.04 & $(.09)$ & -.04 & $(.09)$ \\
\hline Mean employee age & -.18 & $(.09)^{*}$ & -.17 & $(.08)^{*}$ & .13 & $(.07)^{+}$ & .14 & $(.07)^{+}$ \\
\hline Prior year firm performance & -.09 & $(.09)$ & -.02 & $(.09)$ & .09 & $(.07)$ & .09 & $(.08)$ \\
\hline Prior year sick days & .09 & $(.09)$ & .03 & $(.09)$ & .67 & $(.08)^{*}$ & .67 & $(.08)^{*}$ \\
\hline Consumer-centric activity & .02 & $(.09)$ & .07 & $(.09)$ & .00 & $(.07)$ & .00 & $(.07)$ \\
\hline Emotion-focused personnel & & & & & & & & \\
\hline practices & -.03 & $(.08)$ & .01 & $(.08)$ & .08 & $(.07)$ & .11 & $(.07)$ \\
\hline Formalization & -.12 & $(.08)$ & -.08 & $(.08)$ & -.06 & $(.07)$ & -.05 & $(.07)$ \\
\hline Centralization & .26 & $(.13)^{*}$ & .04 & $(.14)$ & .10 & $(.10)$ & .01 & $(.12)$ \\
\hline Positive affective tone & & & -.10 & $(.15)$ & & & -.23 & $(.13)^{+}$ \\
\hline Negative affective tone & & & .42 & $(.14)^{*}$ & & & -.12 & $(.12)$ \\
\hline$D F$ & 11,116 & & 13,114 & & 11,116 & & 13,114 & \\
\hline$R^{2}$ & .30 & & .39 & & .57 & & .58 & \\
\hline$F$ & 4.48 & & 5.50 & & 13.80 & & 12.04 & \\
\hline
\end{tabular}

Note. $N=127-128$ firms, reduced from the full sample of 161 firms due to smaller sample of top management team respondents and missing values for employee sick days. Entries are standardized coefficients and (standard errors).

${ }^{+} p<.10 ;{ }^{*} p<.05 ;$ two-tailed tests 
FIGURE 1

CONCEPTUAL MODEL OF THE ORIGINS AND EFFECTS OF ORGANIZATIONAL AFFECTIVE TONE

\begin{tabular}{|c|c|c|c|}
\hline $\begin{array}{l}\text { ORGANIZATION } \\
\text { DOMAIN }\end{array}$ & $\begin{array}{c}\text { EMBEDDING } \\
\text { MECHANISMS }\end{array}$ & $\begin{array}{l}\text { ORGANIZATIONAL } \\
\text { AFFECTIVE }\end{array}$ & $\begin{array}{c}\text { WORKFORCE } \\
\text { STRAIN }\end{array}$ \\
\hline $\begin{array}{c}\text { Consumer centric } \\
\text { activity }\end{array}$ & $\begin{array}{c}\text { Personnel practices } \\
\text { Formalization } \\
\text { Centralization }\end{array}$ & $\begin{array}{l}\text { Positive } \\
\text { Negative }\end{array}$ & $\begin{array}{l}\text { Exhaustion } \\
\text { Sick days }\end{array}$ \\
\hline
\end{tabular}




\section{FIGURE 2 \\ RESULTS OF PATH ANALYSIS}

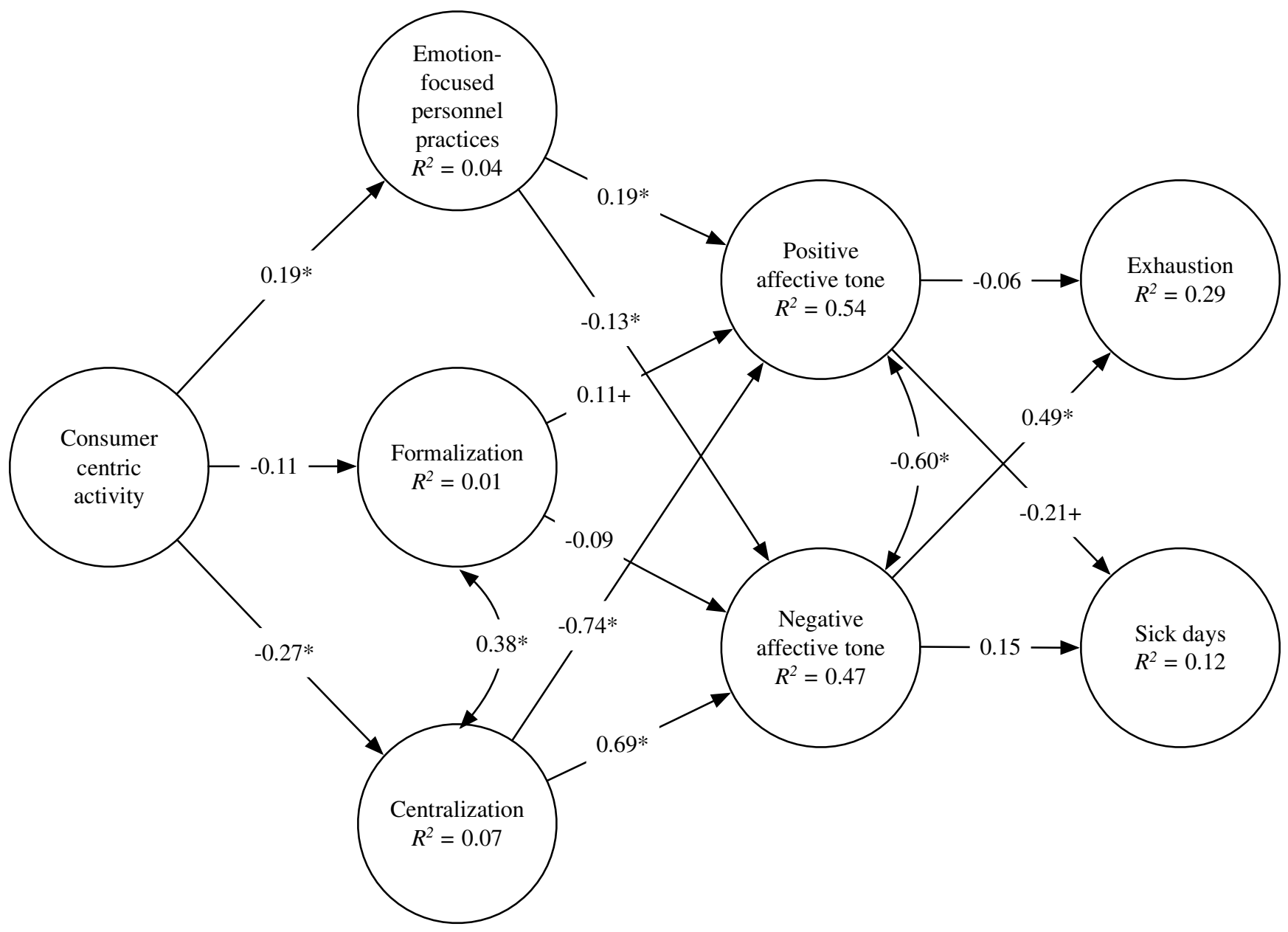

Note. $\mathrm{N}=158$ organizations. Entries are standardized coefficients. Model Fit: $\chi^{2}{ }_{13}=15.34, p=0.29 ; \mathrm{CFI}=0.99 ; \mathrm{TLI}=0.99 ; \mathrm{RMSEA}$ $=0.03 ;$ SRMR $=0.04 .^{+} p<0.10,{ }^{*} p<0.05 ;$ two-tailed tests. 


\section{FIGURE 3}

Plots of Interaction Between Positive Affective Tone and Consumer-Centric Activity Predicting Emotional Exhaustion

A. Traditional interaction plot

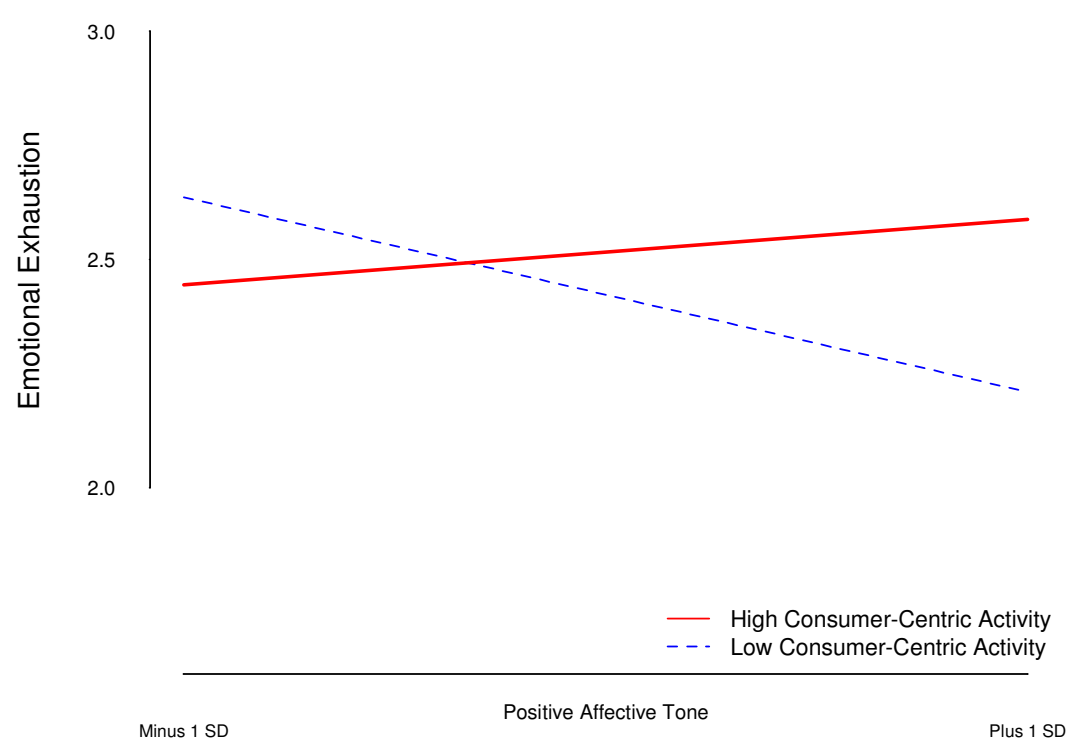

B. Plot of confidence bands around simple slopes

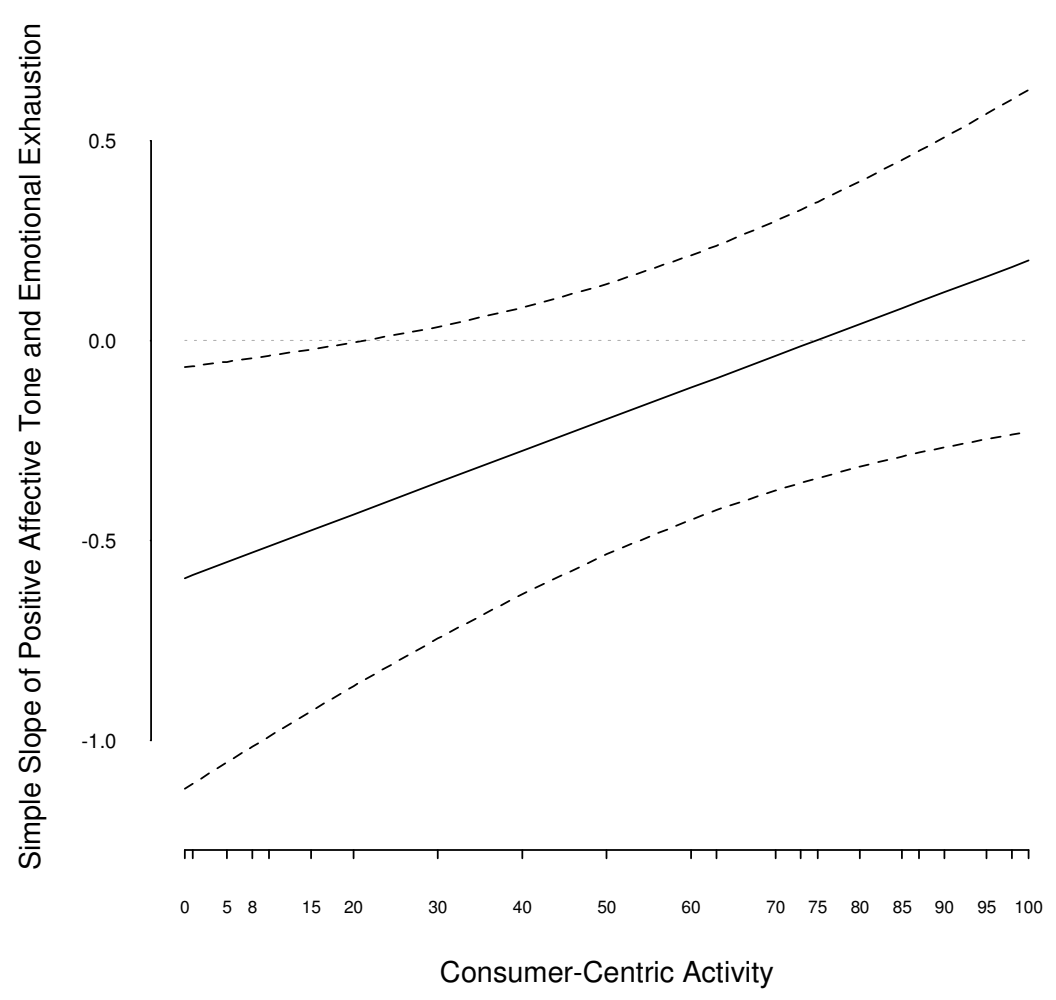

Note. The solid line in Panel B depicts the magnitude of the relationship between affective tone and emotional exhaustion at different levels of consumer-centric activity. The dotted lines in Panel B depict the 95\% confidence interval around these simple slopes. 


\section{FIGURE 4}

Plots of Interaction Between Negative Affective Tone and Consumer-Centric Activity Predicting Employee Sick Days

A. Traditional interaction plot

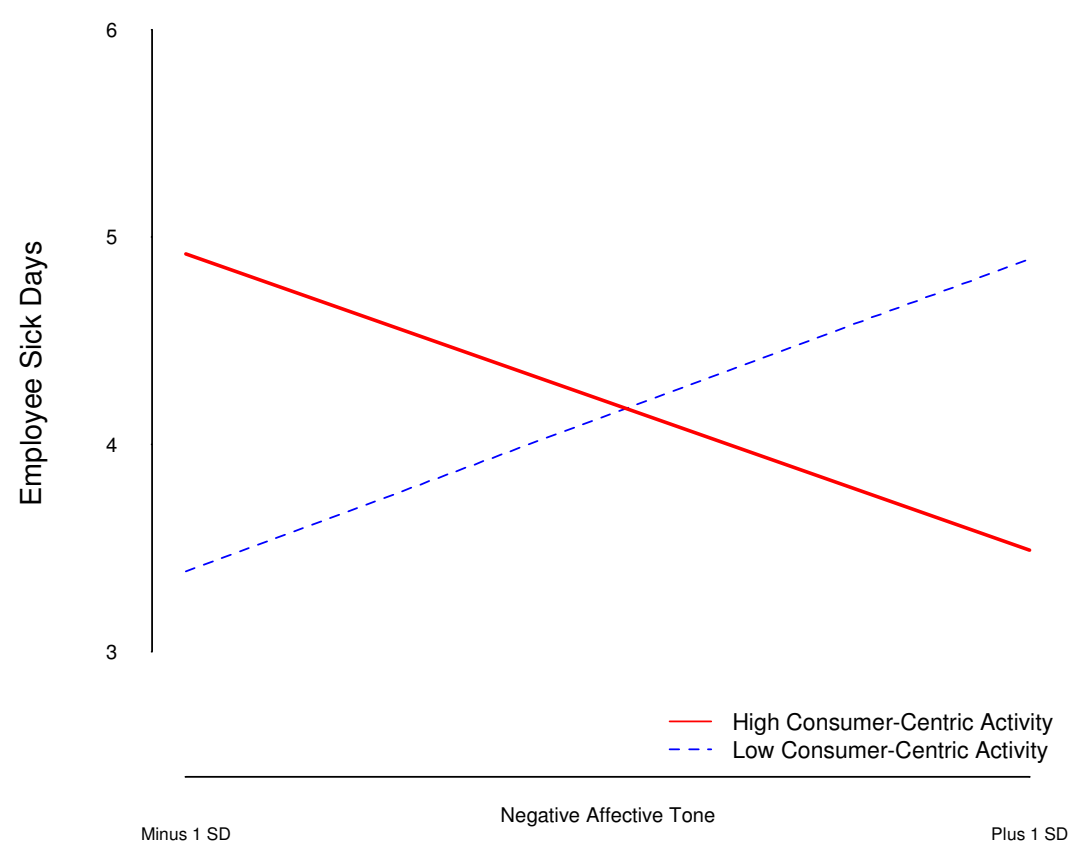

B. Plot of confidence bands around simple slopes

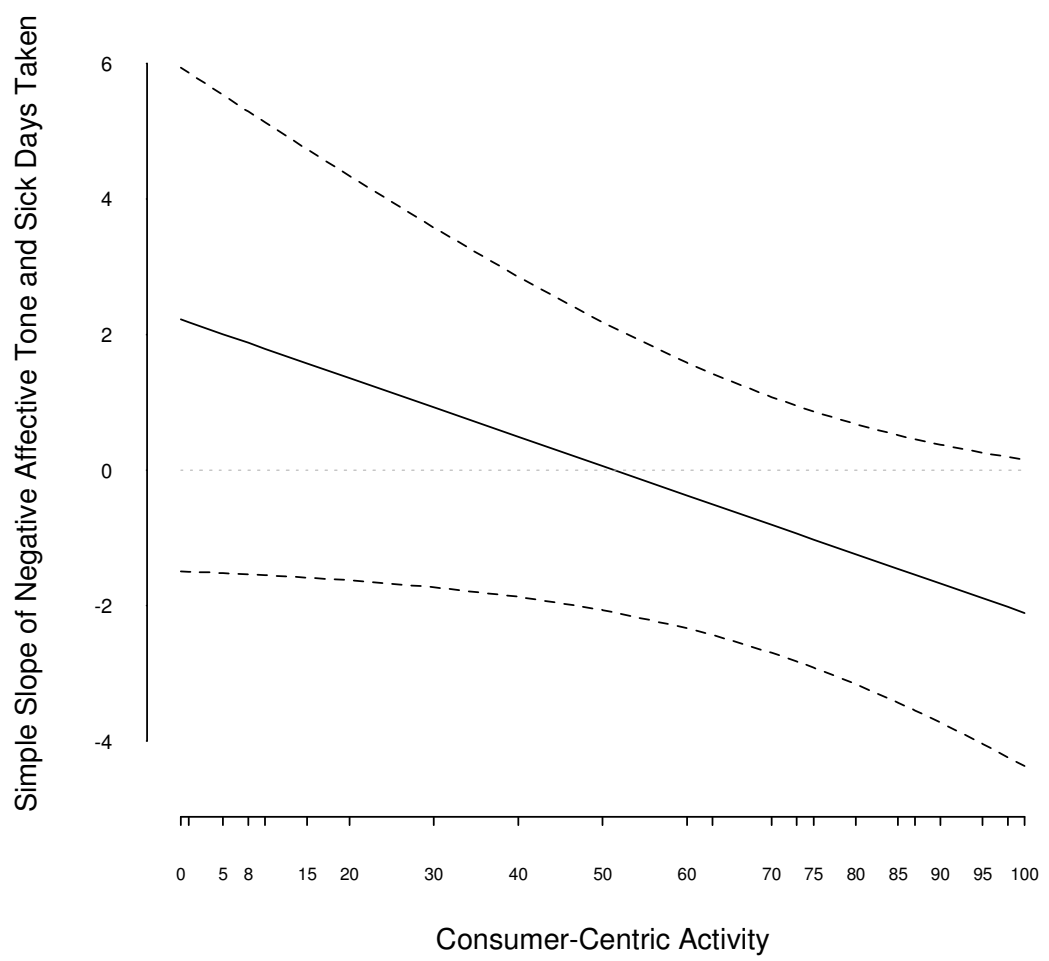

Note. The solid line in Panel B depicts the magnitude of the relationship between affective tone and employee sick days at different levels of consumer-centric activity. The dotted lines in Panel B depict the 95\% confidence interval around these simple slopes. 


\section{Formalization}

\section{APPENDIX: MULTI-ITEM SURVEY MEASURES}

1. For each situation you can think of, there is a written instruction.

2. Rules and practices play a main role in our company.

3. There is a written record of each employee's performance.

4. For positions at all levels in our company there are written job descriptions.

5. Breaches of rules are almost never followed up on. (Reverse-scored)

\section{Centralization}

1. Here employees cannot do anything without their supervisor's permission.

2. Even for small things employees have to get the permission from a supervisor before they can make a final decision.

3. Employees must almost always ask their supervisor for what they should be doing.

4. Someone wanting to make his or her own decision would quickly be discouraged.

5. For most decisions employees make, the supervisor needs to give approval.

\section{Emotion-focused personnel practices}

1. The enthusiasm of job applicants plays an important role in the employment decision.

2. Within our recruitment process, we test specifically how resilient and stress resistant our job applicants are.

3. The ability to handle stress and negative emotions are very important criteria in our employment process.

4. In the selection process we specifically examine the job candidates' capacity for enthusiasm.

5. In our recruiting, we want to specifically appeal to job candidates' emotions.

6. Employees' promotions into leadership positions depend decisively on whether they can inspire enthusiasm in others.

\section{Positive affective tone}

The employees of our company...

1. ....are enthused by their work.

2. ...feel that their work is inspiring.

3. ...feel that their work is exciting.

4. ...feel full of energy at work.

5. ....are euphoric at work.

\section{Negative affective tone}

The employees of our company...

1. ... are angry at work. 
2. ....are afraid at work.

3. ....are furious at work.

4. ....are fed up with their work.

\section{Emotional exhaustion}

1. I feel burned out from my work.

2. I feel already tired when I get up in the morning and have to face another day on the job.

3. I feel frustrated by my job.

4. I feel like I'm at the end of my rope.

\section{Openness of emotional expression (included as a control)}

1. Employees in our company are supposed to only show the emotions that fit to their job profile. (reversed)

2. Employees in our company are supposed to show the emotions that are adequate for their work. (reversed)

3. Employees in our company are supposed to show their emotions openly and honestly.

4. Employees in our company are supposed to show their emotions just as they experience them

\section{BIOGRAPHIES}

Andrew P. Knight (knightap@wustl.edu) is an Associate Professor of Organizational Behavior at the Olin School of Business, Washington University in St. Louis. He received his PhD from the University of Pennsylvania's Wharton School. His research interests include group dynamics, affect, interpersonal relationships, entrepreneurship, and working on papers that belong at the bottom of the stack.

Jochen I. Menges (jochen.menges@whu.edu) holds the Chair of Leadership and HRM at WHU - Otto Beisheim School of Management. He received his PhD in management from the University of St. Gallen, and is appointed as a University Lecturer at the University of Cambridge. His research focuses on leadership, emotions in organizations, and work motivation.

Heike Bruch (heike.bruch@unisg.ch) holds the Chair of Leadership at the University of St. Gallen. She received her PhD in management from the University of Hannover. Her research focuses on leadership, organizational energy and dynamics, and new forms of work. 